\title{
Potential of polarization/Raman lidar to separate fine dust, coarse dust, maritime, and anthropogenic aerosol profiles
}

\author{
Rodanthi-Elisavet Mamouri ${ }^{1,2}$ and Albert Ansmann ${ }^{3}$ \\ ${ }^{1}$ Cyprus University of Technology, Dep. of Civil Engineering and Geomatics, Limassol, Cyprus \\ ${ }^{2}$ The Cyprus Institute, Energy, Environment, and Water Research Center, Nicosia, Cyprus \\ ${ }^{3}$ Leibniz Institute for Tropospheric Research, Leipzig, Germany \\ Correspondence to: Rodanthi-Elisavet Mamouri (rodanthi.mamouri@cut.ac.cy)
}

Received: 26 April 2017 - Discussion started: 4 May 2017

Revised: 28 July 2017 - Accepted: 2 August 2017 - Published: 19 September 2017

\begin{abstract}
We applied the recently introduced polarization lidar-photometer networking (POLIPHON) technique for the first time to triple-wavelength polarization lidar measurements at 355,532 , and $1064 \mathrm{~nm}$. The lidar observations were performed at Barbados during the Saharan Aerosol LongRange Transport and Aerosol-Cloud-Interaction Experiment (SALTRACE) in the summer of 2014. The POLIPHON method comprises the traditional lidar technique to separate mineral dust and non-dust backscatter contributions and the new, extended approach to separate even the fine and coarse dust backscatter fractions. We show that the traditional and the advanced method are compatible and lead to a consistent set of dust and non-dust profiles at simplified, less complex aerosol layering and mixing conditions as is the case over the remote tropical Atlantic. To derive dust mass concentration profiles from the lidar observations, trustworthy extinction-to-volume conversion factors for fine, coarse, and total dust are needed and obtained from an updated, extended Aerosol Robotic Network sun photometer data analysis of the correlation between the fine, coarse and total dust volume concentration and the respective fine, coarse, and total dust extinction coefficient for all three laser wavelengths. Conversion factors (total volume to extinction) for pure marine aerosol conditions and continental anthropogenic aerosol situations are presented in addition. As a new feature of the POLIPHON data analysis, the Raman lidar method for particle extinction profiling is used to identify the aerosol type (marine or anthropogenic) of the non-dust aerosol fraction. The full POLIPHON methodology was successfully applied to a SALTRACE case and the results are discussed. We conclude that the $532 \mathrm{~nm}$ polarization lidar technique has many
\end{abstract}

advantages in comparison to 355 and $1064 \mathrm{~nm}$ polarization lidar approaches and leads to the most robust and accurate POLIPHON products.

\section{Introduction}

Polarization lidar is a very powerful remote sensing tool for aerosol and cloud research. The technique has been used for a long time to monitor and investigate cirrus cloud systems (e.g., Sassen, 1991, 2005; Reichardt et al., 2002, 2008) and polar stratospheric cloud evolution (see, e.g., Browell et al., 1990; Achtert and Tesche, 2014). The method is well suited to study heterogeneous ice formation in mixed-phased clouds (e.g., Sassen et al., 2003; Ansmann et al., 2005, 2008; Ansmann et al., 2009a; Seifert et al., 2010, 2011) and liquidwater cloud developments (e.g., Bissonnette, 2005; Donovan et al., 2015). Meanwhile, polarization lidars are intensively used to explore aerosol mixtures and to identify soil, desert, and volcanic dust (e.g., McNeil and Carswell, 1975; Iwaska and Hayashida, 1981; Winker and Osborn, 1992; Gobbi, 1998; Murayama et al., 1999, 2004; Cairo et al., 1999; Gobbi et al., 2000; Sakai et al., 2003; Sassen et al., 2007; Freudenthaler et al., 2009; Ansmann et al., 2010; Ansmann et al., 2011a; Groß et al., 2012; Miffre et al., 2012; Amiridis et al., 2013; Nisantzi et al., 2014). The technique permits the discrimination of desert dust or volcanic dust from other aerosols such as biomass-burning smoke, maritime particles, or urban haze (e.g., Sugimoto et al., 2003; Shimizu et al., 2004; Nishizawa et al., 2007; Tesche et al., 2009a; Ansmann et al., 2012). Another fruitful field is related 
to aerosol typing, which is based on combined data sets of the particle extinction-to-backscatter ratio (lidar ratio) measured with Raman lidar or high-spectral-resolution lidar (HSRL) and the particle linear depolarization ratio obtained from polarization lidar observations (e.g., Burton et al., 2012, 2013; Groß et al., 2013, 2015; Illingworth et al., 2015). Recently, we broadened the application spectrum of the polarization lidar technique by introducing the POLIPHON (polarization lidar-photometer networking) method for estimating fine dust (particles with radius $<500 \mathrm{~nm}$ ) and coarse dust mass concentration profiles from single-wavelength polarization lidar measurements (Mamouri and Ansmann, 2014). Furthermore, we demonstrated that polarization lidars have the potential to contribute to vertical profiling of cloud condensation nucleus (CCN) and ice-nucleating particle (INP) concentrations (Mamouri and Ansmann, 2015, 2016).

The retrieval of these higher level lidar products is driven by the fact that state-of-the-art environmental (regional) and global atmospheric models include aerosol schemes which simulate microphysical aerosol processes and life cycles of a variety of aerosol components and can be used to predict dust events and enable the simulation of CCN and INP profiles (Huneeus et al., 2011; Koffi et al., 2012, 2016; Mann et al., 2014; Kim et. al., 2014; Nickovic et al., 2016; Hande et al., 2016). These models allow detailed dust climate impact studies and forecasts of fine and coarse dust fractions and thus of the fine dust contribution to the measured overall fine particle concentration $\left(\mathrm{PM}_{1}\right.$, particles with diameters $\left.<1 \mu \mathrm{m}\right)$, which is of great interest for environmental services (air-quality management), especially in areas close to deserts. It is important to quantify the natural impact of fine and coarse dust on recorded aerosol pollution levels measured as $\mathrm{PM}_{1}, \mathrm{PM}_{2.5}$ (particle diameter $<2.5 \mu \mathrm{m}$ ), and $\mathrm{PM}_{10}$ (particle diameter $<10 \mu \mathrm{m}$ ). However, dust modeling is associated with moderate to high uncertainties in the predictions and thus needs to be accompanied by advanced dust profile observations. In a review article, Huneeus et al. (2011) emphasized the need for height-resolved observations of dust-size-characterizing parameters to support dust modeling. Kok et al. (2017) discussed in detail the consequences of a poorly modeled dust size distribution (overestimation of the dust fine-mode fraction) for the global energy balance through direct interaction of dust with radiation because fine and coarse dust fractions show significantly different radiative influences (Nabat et al., 2012; Ridley et al., 2016). Recent lidar-model comparisons indicate that dust models tend to overestimate the dust fine fraction (Ansmann et al., 2017).

Lidar plays an important role in dust monitoring efforts because it is the optimum aerosol profiling technique. The increasing potential of present and future atmospheric modeling makes it necessary to explore to what extent lidar can support numerical modeling by providing height-resolved observations of the most relevant aerosol parameters such as the fine and coarse dust fractions. The advantage of the POLIPHON method, of which the latest developments are presented in this article, is that this technique does not need a critical dust particle shape model in the data analysis, as required in alternative lidar-photometer retrieval schemes (Chaikovsky et al., 2012; Lopatin et al., 2013; Torres et al., 2016). Another advantage is that the POLIPHON method is based on single-wavelength lidar observations, and as such the method is likewise simple and robust and can be easily automatized and applied to continuously measured large data sets. An important advantage is that the technique can be used at cloudy conditions. The alternative lidar-photometer approaches need clear skies, which are often not given during dust outbreak events. The robust POLIPHON method is thus well suited for environmental studies and aerosol-cloud interaction research.

In this article, we extend the methodology for fine and coarse dust separation developed for $532 \mathrm{~nm}$ towards 355 and $1064 \mathrm{~nm}$ lidar wavelengths. A dense set of high-quality observational data obtained with a triple-wavelength polarization lidar collected in the framework of the Saharan Aerosol Long-Range Transport and Aerosol-Cloud-Interaction Experiment (SALTRACE) is available for this study (Haarig et al., 2017a). The importance of such a multi-wavelength effort arises from the fact that NASA's spaceborne polarization lidar CALIOP (Cloud Aerosol Lidar with Orthogonal Polarization; Winker et al., 2009) is operated at $532 \mathrm{~nm}$, whereas ESA's future spaceborne aerosol lidar ATLID (Atmospheric Lidar) will be operated at $355 \mathrm{~nm}$ (Illingworth et al., 2015), and to homogenize these different polarization lidar data sets a good knowledge about the compatibility of 355 and $532 \mathrm{~nm}$ retrieval schemes is required. In this article, we will discuss which of the available three lidar wavelengths is the optimum one and produces the most robust and accurate retrieval data sets when using the POLIPHON method.

Another favorable aspect to further explore the applicability of the POLIPHON analysis scheme is that recently the results of a comprehensive laboratory study on particle linear depolarization ratios for a variety of soil and desert dust types were published (Järvinen et al., 2016). The most interesting point is that all measurements were performed as a function of dust particle size. In this way, for the first time, very detailed information on fine dust depolarization ratios became available and can be used in the POLIPHON methodology which was based before on a few laboratory measurements of fine- and coarse-dust-dominated linear depolarization ratios (Sakai et al., 2010) and simulation studies by Gasteiger et al. (2011). Recent new field observations in advected thick dust plumes over Senegal in western Africa (Veselovskii et al., 2016) and Tajikistan in central Asia (Hofer et al., 2017) corroborate the laboratory findings. In addition, more modeling studies became available (Kemppinen et al., 2015a, b), presenting results in terms of dust lidar ratio and depolarization ratio for irregularly shaped particles as a function of size. We will review the compiled information on recent dust depolarization model, laboratory, and field studies in Sect. 2. 
The paper contains six sections. In Sect. 3, the SALTRACE field campaign, the lidar observations, and the Aerosol Robotic Network (AERONET) data sets (Holben et al., 1998) used in this article are introduced and briefly described. The theoretical background of the POLIPHON method is outlined in Sect. 4. Particle extinction-to-volume conversion factors for the used laser wavelengths and basic aerosol types (marine, continental pollution, desert dust) are required to retrieve mass concentration profiles. These factors are quantified on the basis of multiyear and shortterm (field campaign) AERONET observations. The main results are presented in Sect. 5. An extended case study of a POLIPHON data analysis is then given in Sect. 6 for a SALTRACE measurement performed in the summer of 2014. All available POLIPHON approaches (the traditional, well-established one-step and the new advanced two-step POLIPHON method and the combination of both methods) are applied and compared, and the POLIPHON method is applied to all three laser wavelengths. Concluding remarks are given in Sect. 7.

\section{Review of recent field, laboratory, and modeling studies of dust-related particle linear depolarization ratios}

\subsection{Laboratory studies}

Järvinen et al. (2016) measured the particle linear depolarization ratio in the large cloud simulation chamber AIDA (Aerosol Interaction and Dynamics in the Atmosphere) of the Karlsruhe Institute of Technology, filled with natural probes of dust from different deserts in Africa, Asia, and America. They were able to inject dust particles of a specific size class (mode) into the chamber and thus to perform observations as a function of the size parameter $(\pi D / \lambda$ with laser wavelength $\lambda$ and particle-mode diameter $D$ ). The studies were performed at a wavelength of $488 \mathrm{~nm}$, partly also at $552 \mathrm{~nm}$, and considered dust particles up to size parameters of 20 (and thus up particle diameters of about $3 \mu \mathrm{m}$ ). From this work, we estimated the particle linear depolarization for fine dust for all three wavelengths. These values are given in Table 1 . Fine dust causes particle depolarization ratios around $0.21 \pm 0.02,0.16 \pm 0.02$, and $0.09 \pm 0.03$ for the laser wavelengths of 355,532 , and $1064 \mathrm{~nm}$, respectively. These values are in agreement with the laboratory findings of Sakai et al. (2010), who found dust particle depolarization ratios of $0.14-0.17 \pm 0.03$ for fine-dust-dominated particle ensembles at $532 \mathrm{~nm}$. The fine dust depolarization ratio for $532 \mathrm{~nm}$ is also in good agreement with modeling studies (Gasteiger et al., 2011). However, conclusions on the depolarization ratio for atmospheric coarse dust size distributions cannot be drawn. Järvinen et al. (2016) stated that gravitational settling in the chamber had a strong impact on their measurement with large dust particles so that most reliable results are avail-
Table 1. Typical fine and coarse dust linear depolarization ratios, $\delta_{\mathrm{df}}$ and $\delta_{\mathrm{dc}}$, respectively, as estimated from published laboratory studies (1: Järvinen et al., 2016; 2: Sakai et al., 2010) and field observations (3: Freudenthaler et al., 2009; 4: Burton et al., 2015; 5: Veselovskii et al., 2016; 6: Haarig et al., 2017a; 7: Hofer et al., 2017).

\begin{tabular}{lrr}
\hline Wavelength & $\delta_{\mathrm{df}}$ & $\delta_{\mathrm{dc}}$ \\
\hline $355 \mathrm{~nm}$ & $0.21 \pm 0.02(1)$ & $0.27 \pm 0.03(4,7)$ \\
$532 \mathrm{~nm}$ & $0.16 \pm 0.02(1,2)$ & $0.37 \pm 0.03(2,4,5,7)$ \\
$1064 \mathrm{~nm}$ & $0.09 \pm 0.02(1)$ & $0.27 \pm 0.03(3,4,6)$ \\
\hline
\end{tabular}

able for dust size parameters $<10$ only. The laboratory studies of Sakai et al. (2010) yielded particle linear depolarization ratios of about $0.39-0.4$ at $532 \mathrm{~nm}$ for coarse dust ensembles (Asian and Saharan dust probes).

\subsection{Field observations}

Table 1 also contains the coarse dust depolarization ratios we use in our POLIPHON method. These values are mostly derived by combining the laboratory studies (of the fine dust depolarization ratios) and a variety of field observations of the total (fine + coarse) dust depolarization ratio. Burton et al. (2015) reported high particle linear depolarization ratios around 0.4 for 532 and $1064 \mathrm{~nm}$, as found by Sakai et al. (2010), in dense dust plumes over the United States close to the ground and probably close to the dust sources with a strongly dominating coarse mode. Veselovskii et al. (2016) and Hofer et al. (2017) found maximum particle depolarization ratios around 0.35 at $532 \mathrm{~nm}$, respectively, in dense western African and central Asian dust plumes. The accompanying AERONET sun photometer observations indicated an extinction-related fine-mode fraction (FMF) of 10-15\% (at $500 \mathrm{~nm}$ ). If we assume that the backscatter-related FMF, denoted as BFMF, is equal to $\mathrm{FMF}=0.15$, the coarse dust depolarization ratio is again close to $0.39-0.4$ when assuming a fine dust depolarization ratio of, for example, 0.16 . Then the total (fine + coarse) depolarization ratio is about 0.35 . Note that the overall dust depolarization ratio can be calculated from the fine and coarse dust backscatter coefficients with Eq. (2) in Mamouri and Ansmann (2014) when exchanging the terms with index $\mathrm{p}$ (for particle), nd (for non-dust), and $\mathrm{d}$ (for dust) in Eq. (2) with the respective ones with index d, df (for fine dust), and dc (for coarse dust).

The numerous field observations indicate that the total dust linear depolarization ratio is always around 0.3 at $532 \mathrm{~nm}$ (close to the dust sources as well as after long-range transport). In contrast, the $1064 \mathrm{~nm}$ dust depolarization ratio was found to vary strongly from values of 0.22 to 0.28 for lofted dust layers (and typical dust size distribution after regional as well as long-distance travel; Freudenthaler et al., 2009; Burton et al., 2015; Haarig et al., 2017a) to values around 0.4 (Burton et al., 2015) close to dust sources. Only during events close to dust emission zones when giant dust parti- 
cles and even sand particles (having diameters $>60 \mu \mathrm{m}$ ) are in the air, such very high particle linear depolarization ratios are obviously measurable at $1064 \mathrm{~nm}$. This is corroborated by $710 \mathrm{~nm}$ depolarization ratio studies during the occurrence of dust devils in Morocco (Ansmann et al., 2009a).

According to AERONET dust observations the FMF at $1020 \mathrm{~nm}$ is typically in the range of $0.05-0.08$ during dust outbreaks so that the $1064 \mathrm{~nm}$ dust depolarization ratio is then almost completely controlled by coarse dust, if we assume again that BFMF is in the same range as FMF. The maximum values for the $1064 \mathrm{~nm}$ total dust depolarization ratio measured over Barbados of 0.27 (Haarig et al., 2017a) are therefore almost equal to the coarse dust depolarization ratio. Even over Morocco, maximum $1064 \mathrm{~nm}$ depolarization ratios were significantly below 0.3 with values of 0.28 (Freudenthaler et al., 2009).

We can only speculate about the reason for the significantly different coarse dust depolarization ratio at $1064 \mathrm{~nm}$ $(<0.3)$ and $532 \mathrm{~nm}(0.35-0.39)$. Simulation studies of Kemppinen et al. (2015b) show a possible way of explanation. Their simulations are based on realistic dust particle shapes sampled during the Saharan Mineral Dust Experiment (SAMUM-1) in Morocco (Lindqvist et al., 2014). For the socalled dolomite shape type, the simulations of Kemppinen et al. (2015b) yield particle linear depolarization ratios of $0.35-0.4$ and $0.2-0.25$ at 532 and $1064 \mathrm{~nm}$, respectively, in the case of dust particles with diameters around $2 \mu \mathrm{m}$. It is worthwhile to mention in this context that the AERONET photometer observations during dust outbreaks over Barbados in 2013 and 2014 show that the coarse-mode effective diameter accumulated around $3 \pm 0.4 \mu \mathrm{m}$, which indicates that most coarse dust particles after long-range transport have diameters in the 1-3 $\mu \mathrm{m}$ size range. Veselovskii et al. (2016) retrieved overall (fine dust + coarse dust) effective diameters of 2-2.5 $\mu \mathrm{m}$ from the multiwavelength lidar measurements in the dust plumes over Senegal during the SHADOW (Study of SaHAran Dust Over West Africa) campaign in March and April 2015. Aircraft observations (in situ aerosol measurements) over Cabo Verde and Barbados indicate a pronounced dust size mode around 1-2 $\mu \mathrm{m}$ diameter and a strong drop in number concentration for diameters of $>3 \mu \mathrm{m}$ (Weinzierl et al., 2017).

The dust linear depolarization ratio at $355 \mathrm{~nm}$ seems to be always close to 0.25 (Groß et al., 2011, 2015; Burton et al., 2015; Haarig et al., 2017a), disregarding the distance from the dust source and strength of the outbreak and occurring particle sizes. Even during rather strong dust storms in central Asia, Hofer et al. (2017) found maximum $355 \mathrm{~nm}$ depolarization ratios of 0.29 only. AERONET sun photometer observations typically point to FMF values of $0.3-0.5$ for the wavelength of $380 \mathrm{~nm}$ during dust events. Obviously, the $355 \mathrm{~nm}$ depolarization ratio is always strongly influenced by submicrometer dust particles. If we now consider a fine dust linear depolarization ratio of 0.21 (according to the laboratory study of Järvinen et al., 2016) and a fine-mode backscat- ter fraction of 0.5 , we end up with a coarse dust depolarization ratio in the range of $0.27-0.3$, which is in agreement with the observations of 0.29 of Hofer et al. (2017).

\section{Experimental data}

\subsection{SALTRACE field campaign}

The SALTRACE field studies were conducted at the Caribbean island of Barbados in June-July 2013 (SALTRACE-1), February-March 2014 (SALTRACE2), and June-July 2014 (SALTRACE-3). An overview of the SALTRACE field activities and goals can be found in Weinzierl et al. (2017) and Haarig et al. (2017a). Triplewavelength polarization lidar observations of lofted dust layers were performed at the Caribbean Institute of Meteorology and Hydrology (CIMH, $13.1^{\circ} \mathrm{N}, 59.6^{\circ} \mathrm{W} ; 90 \mathrm{~m}$ above sea level) about $5000-8000 \mathrm{~km}$ downwind of the main Saharan dust source regions. We selected a measurement conducted in June 2014 to demonstrate the potential of the extended POLIPHON method. SALTRACE provided excellent conditions to test and check different POLIPHON retrieval concepts. Over Barbados (during the summer seasons), well-defined, almost-pure dust conditions in the lofted Saharan air layer (SAL) between 1.5 and $5.5 \mathrm{~km}$ height prevail as well as well-defined marine and dust particle mixing states in the marine aerosol layer (MAL) below the SAL are usually given. At these conditions the consistency of results obtained by applying the different dust discrimination techniques (one-step and two-step methods) could be tested in detail.

\subsection{Triple-wavelength polarization lidar}

The containerized multiwavelength polarization/Raman lidar BERTHA (Backscatter Extinction lidar-Ratio Temperature Humidity profiling Apparatus; Althausen et al., 2000; Haarig et al., 2017a) was involved in 12 major aerosolrelated field campaigns in Europe, Asia, and Africa over the last 20 years. The advanced lidar was re-designed in 2012 to allow particle linear depolarization measurements at 355,532 , and $1064 \mathrm{~nm}$, simultaneously. The fundamental quantities measured with lidar and input in the POLIPHON retrieval are the particle linear depolarization ratio and the particle backscatter coefficient for a given wavelength. The determination of these basic aerosol parameters from the polarization-sensitive BERTHA signals is described by Haarig et al. (2017a). Furthermore, the case study used here as the POLIPHON demonstration case in Sect. 6 is described in detail in terms of the aerosol optical properties by Haarig et al. (2017a). 


\subsection{AERONET sun photometry}

An important prerequisite of the POLIPHON methodology is the existence of a close relationship between the lidarderived particle extinction coefficient and the particle volume concentration, which allows us to compute the desired mass concentration profiles from the measured particle optical properties. We need these extinction-to-volume conversion factors for the basic aerosol types - i.e., for marine, anthropogenic, and dust aerosols - and, in the case of dust, even separately for fine dust and coarse dust. The correlation between particle extinction coefficient and particle volume concentration is intensively studied in Sect. 5 based on longterm AERONET sun photometer observations at Limassol (Cyprus), Leipzig (Germany), and Ragged Point (Barbados), as well as on measurements during dedicated field campaigns such as SAMUM-1 (Morocco, 2006), SAMUM2 (Cabo Verde, 2008), and SALTRACE (Barbados, 20132014; AERONET, 2016). The study makes use of the same AERONET data sets for desert, marine, and polluted continental sites as described in detail already by Mamouri and Ansmann (2016) in their study on CCN and INP profiling with polarization lidar.

Fourteen years of AERONET observations at Leipzig, Germany, performed by the Leibniz Institute for Tropospheric Research (TROPOS) from 2001 to 2015 and 4 years of AERONET observations at Limassol, Cyprus, performed by the Cyprus University of Technology (CUT) from 2011 to 2015 (Nisantzi et al., 2014, 2015) are available for our studies. Aerosol mixtures of anthropogenic haze, biomass-burning smoke, soil and road dust, and marine particles as well as strong dust outbreaks from Middle Eastern deserts and the Sahara frequently occur over Cyprus (Nisantzi et al., 2015). Pure dust observations are available from SAMUM-1 (Ouarzazate, Morocco; Toledano et al., 2009), SAMUM-2 (Praia, Cabo Verde; Toledano et al., 2011), and SALTRACE field observations (Weinzierl et al., 2017). The dust data sets allow us to study the extinctionto-volume correlation separately for fine, coarse, and total dust. Furthermore, we used 7.5 years of data from the AERONET station at Ragged Point, Barbados (Prospero and Mayol-Bracero, 2013), to study the correlation between the aerosol extinction coefficient and volume concentration for pure marine conditions. An overview of the observational periods and amount of available data for the analyzed different aerosol conditions with focus on the three defined aerosol types can be found in Table 1 in Mamouri and Ansmann (2016). More details of these AERONET stations are given on the AERONET web page (http://aeronet.gsfc.nasa.gov). Dubovik et al. (2000) carried out a detailed analysis of uncertainties in the AERONET products. Errors in the basic measurements of the aerosol optical thickness (AOT) are low (on the order of 0.01 ) and about $10-20 \%$ for the retrieved particle volume concentrations.

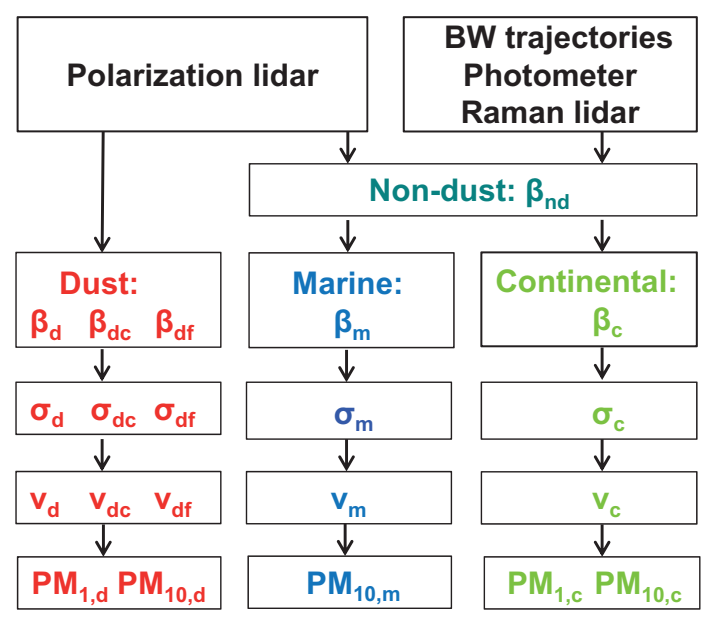

Figure 1. Overview of the POLIPHON data analysis. The depolarization ratio measurement enables us to separate the backscatter coefficients of fine dust, $\beta_{\mathrm{df}}$, coarse dust, $\beta_{\mathrm{dc}}$, and of the nondust aerosol component, $\beta_{\text {nd }}$. The non-dust backscatter coefficients are subsequently analyzed by using backward trajectories, auxiliary spectrally resolved photometer observations, and, if available, Raman lidar observations of the total particle extinction coefficient to identify and quantify the contribution of marine particles $\left(\beta_{\mathrm{m}}\right)$ and continental aerosol pollution $\left(\beta_{\mathrm{c}}\right)$ to the total particle backscatter coefficient. The backscatter coefficients $\beta_{i}$ are converted to particle extinction coefficients $\sigma_{i}$, which in turn are converted to profiles of particle volume concentrations $v_{i}$. Finally, the respective particle mass (PM) concentrations for fine particles, $\mathrm{PM}_{1, i}$, and for fine + coarse particles, $\mathrm{PM}_{10, i}$, can be calculated. Non-dust continental particles are mostly fine-mode aerosol so that $\mathrm{PM}_{1, \mathrm{c}}$ is obtained, too.

\section{POLIPHON method}

The POLIPHON concept (Mamouri and Ansmann, 2014) was introduced to separate dust and non-dust aerosol components and to estimate the fine and coarse dust contributions to the overall backscatter and extinction coefficients and particle mass concentration. Of key importance is the avoidance of a particle shape model for the irregularly shaped mineral dust particles in the retrieval scheme. The method is solely based on the use of characteristic depolarization ratios for fine dust, coarse dust, and non-dust aerosol. In Sect. 2, field observations and available laboratory studies of these required desert dust depolarization ratios were reviewed. An overview of the data analysis scheme is given in Fig. 1. All retrieval steps are explained in Sect. 4.1-4.5.

We start with a brief overview of the full methodology. The POLIPHON approach comprises both the traditional retrieval (here denoted as one-step method) to separate dust and non-dust backscatter profiles and the recently introduced so-called two-step POLIPHON method (Mamouri and Ansmann, 2014). As presented in Sect. 4.1, the one-step method permits the separation of the dust and non-dust components in one step, but no further separation into fine and coarse 
dust fractions. This method is the classic, well-established way of dust separation by means of the measured particle linear depolarization ratio (e.g., Sugimoto et al., 2003; Shimizu et al., 2004; Tesche et al., 2009a). In contrast, two steps are required to separate non-dust, fine dust, and coarse dust components (Sect. 4.2). In the first step, the coarse dust fraction is separated. In the second step, the remaining fine dust plus non-dust backscatter is analyzed and the fine dust and non-dust fractions are separated. The different retrieval schemes are illustrated in Fig. 1 of Mamouri and Ansmann (2014). The consistency between the one-step and the twostep method is discussed in Sect. 4.6 and demonstrated in Sect. 6 (SALTRACE case study).

To convert the obtained aerosol-type-dependent backscatter coefficients into respective extinction coefficients, characteristic lidar ratios for fine dust, coarse dust, and the nondust component are required (Sect. 4.3). These extinctionto-backscatter ratios are taken from the literature. Although simulations suggest different lidar ratios for fine and coarse dust (Gasteiger et al., 2011; Kemppinen et al., 2015a, b), we assume just the same lidar ratio for fine, coarse, and total dust.

As a new aspect of the extended POLIPHON method, we make use of the Raman lidar solution for the overall particle extinction coefficient (see Haarig et al., 2017a, for more details of this retrieval) to identify the non-dust aerosol type (marine or continental anthropogenic or even a mixture of both; see Sect. 4.4 and Fig. 1). Finally, extinction-to-volume conversion factors obtained from an extended AERONET data analysis (presented in Sect. 5) are used together with assumed particle densities (for marine, anthropogenic, and dust particles) to obtain particle mass concentration profiles for fine dust $\left(\mathrm{PM}_{1, \mathrm{~d}}\right)$, coarse dust $\left(\mathrm{PM}_{10, \mathrm{~d}}-\mathrm{PM}_{1, \mathrm{~d}}\right)$, total dust $\left(\mathrm{PM}_{10, \mathrm{~d}}\right)$, anthropogenic aerosol $\left(\mathrm{PM}_{10, \mathrm{c}}\right.$, usually finemode particles only, $\left.\mathrm{PM}_{1, \mathrm{c}}\right)$, and marine aerosol $\left(\mathrm{PM}_{10, \mathrm{~m}}\right)$, according to the equations presented in Sect. 4.5.

\subsection{One-step POLIPHON method}

Because a detailed description of the basic POLIPHON data analysis procedure is given in Mamouri and Ansmann (2014), we only present the set of equations needed in the data analysis starting from the measured height profiles of the particle linear depolarization ratio $\delta_{\mathrm{p}}$ and particle backscatter coefficient $\beta_{\mathrm{p}}$. In the one-step approach, the dust backscatter coefficient $\beta_{\mathrm{d}}$ and the non-dust backscatter coefficient $\beta_{\text {nd }}$ are obtained with the following set of equations:

$$
\begin{aligned}
& \beta_{\mathrm{d}}=\beta_{\mathrm{p}} \frac{\left(\delta_{\mathrm{p}}-\delta_{\mathrm{nd}}\right)\left(1+\delta_{\mathrm{d}}\right)}{\left(\delta_{\mathrm{d}}-\delta_{\mathrm{nd}}\right)\left(1+\delta_{\mathrm{p}}\right)} \text { for } \delta_{\mathrm{nd}}<\delta_{\mathrm{p}}<\delta_{\mathrm{d}}, \\
& \beta_{\mathrm{d}}=\beta_{\mathrm{p}} \text { for } \delta_{\mathrm{p}} \geq \delta_{\mathrm{d}}, \\
& \beta_{\mathrm{d}}=0 \text { for } \delta_{\mathrm{p}} \leq \delta_{\mathrm{nd}}, \\
& \beta_{\mathrm{nd}}=\beta_{\mathrm{p}}-\beta_{\mathrm{d}} .
\end{aligned}
$$

The assumed quantities are the overall (fine + coarse) dust depolarization ratio $\delta_{\mathrm{d}}$ and the non-dust depolarization ratio $\delta_{\text {nd }}$. In Sect. 6, we use total dust depolarization ratios of $\delta_{\mathrm{d}}$ of $0.25(355 \mathrm{~nm}), 0.31(532 \mathrm{~nm})$, and 0.27 (1064 nm). For $\delta_{\mathrm{nd}}$ we assume 0.05 , considering minor contributions to depolarization by dried marine particles (Haarig et al., 2017b) or by anthropogenic particles.

\subsection{Two-step POLIPHON method}

As mentioned above, two subsequent steps of computations are required to obtain height profiles of non-dust, fine dust, and coarse dust backscatter height profiles. In step 1, we separate the height profile of the coarse dust backscatter fraction from the remaining aerosol backscatter caused by non-dust and fine dust particles. We assume that coarse dust produces a linear depolarization ratio, $\delta_{\mathrm{dc}}$, of 0.39 at $532 \mathrm{~nm}, 0.27$ at $355 \mathrm{~nm}$, and 0.28 at $1064 \mathrm{~nm}$ (see Table 1 and Sect. 6).

As an important task in the first round, we have to estimate the depolarization ratio $\delta_{\mathrm{nd}+\mathrm{df}, \mathrm{e}}$ for the remaining aerosol (mixture of non-dust particles, indicated by index nd, and fine dust, indicated by index df). The index e emphasizes that $\delta_{\text {nd }+d f, e}$ is estimated in the first round. This estimation is difficult, however. Accompanying AERONET observations of FMF provide information regarding the relative contribution of fine-mode aerosol (contributions from marine, dust, and pollution sources) to the overall aerosol load. In addition, we may use rough estimates for the fine particle backscatter and extinction fractions of $0.2-0.3$ for pure marine or pure dust aerosols at $532 \mathrm{~nm}$ (both have similar size distributions as the AERONET long-term observations indicate) and of 0.9 for anthropogenic and biomass-burning smoke. Together with the measured profile of the particle depolarization ratio, all this information may help to estimate the non-dust aerosol fraction and the fine dust aerosol fraction as outlined in Mamouri and Ansmann (2014). By applying Eq. (2) in Mamouri and Ansmann (2014) we can obtain the respective depolarization ratio $\delta_{\text {nd }+ \text { df,e }}$ for the mixture of non-dust and fine dust when exchanging the terms with index $p$ (for particle) and $d$ (for dust) by respective ones with index nd $+\mathrm{df}$ and df in this equation. Because of this difficult estimation we recommend using both the one-step and the two-step method in the lidar data analysis. In the one-step method, $\delta_{\text {nd }+ \text { df }}$ is not needed. Thus, the non-dust and dust profiles obtained with the one-step method can help to find the optimum values (height profile) of $\delta_{\text {nd }+ \text { df }}$ so that, at the end, the profiles of the total dust backscatter coefficient and the corresponding non-dust backscatter coefficient determined with the onestep and the two-step method match. In Sect. 4.6, we describe how to use both methods in the data analysis to overcome this problem of estimating $\delta_{\text {nd+df,e }}$. In Sect. 6, we apply this combined one-step-two-step data analysis procedure to the selected SALTRACE lidar observation.

The coarse dust backscatter coefficient $\beta_{\mathrm{dc}}$ and the backscatter coefficient $\beta_{\text {nd }+ \text { df }}$ of the residual aerosol mixture 
are obtained by means of the estimated input value $\delta_{\text {nd }+ \text { df,e }}$ and the following set of equations (Mamouri and Ansmann, 2014):

$$
\begin{aligned}
& \beta_{\mathrm{dc}}=\beta_{\mathrm{p}} \frac{\left(\delta_{\mathrm{p}}-\delta_{\mathrm{nd}+\mathrm{df}, \mathrm{e}}\right)\left(1+\delta_{\mathrm{dc}}\right)}{\left(\delta_{\mathrm{dc}}-\delta_{\mathrm{nd}+\mathrm{df}, \mathrm{e}}\right)\left(1+\delta_{\mathrm{p}}\right)} \\
& \text { for } \delta_{\mathrm{nd}+\mathrm{df}, \mathrm{e}}<\delta_{\mathrm{p}}<\delta_{\mathrm{dc}}, \\
& \beta_{\mathrm{dc}}=\beta_{\mathrm{p}} \text { for } \delta_{\mathrm{p}} \geq \delta_{\mathrm{dc}}, \\
& \beta_{\mathrm{dc}}=0 \text { for } \delta_{\mathrm{p}} \leq \delta_{\mathrm{nd}+\mathrm{df}, \mathrm{e}}, \\
& \beta_{\mathrm{nd}+\mathrm{df}}=\beta_{\mathrm{p}}-\beta_{\mathrm{dc}} .
\end{aligned}
$$

The coarse dust depolarization ratio is given in Table 1 . Eqs. (5)-(8) can be used to analyze the lidar observations separately for each of the three wavelengths.

Before we can proceed with step 2, we need to remove the coarse dust contributions to the particle depolarization ratio (Mamouri and Ansmann, 2014):

$\delta_{\mathrm{nd}+\mathrm{df}}=\delta_{\mathrm{p}}$ for $\delta_{\mathrm{p}}<\delta_{\mathrm{nd}+\mathrm{df}, \mathrm{e}}$,

$\delta_{\text {nd }+\mathrm{df}}=\delta_{\text {nd }+\mathrm{df}, \mathrm{e}}$ for $\delta_{\mathrm{p}} \geq \delta_{\mathrm{nd}+\mathrm{df}, \mathrm{e}}$.

In the following, $\delta_{\text {nd }+ \text { df }}$ is used without index e.

In step 2, we now can separate the fine dust backscatter coefficient $\beta_{\mathrm{df}}$ and the non-dust aerosol backscatter coefficient $\beta_{\text {nd }}$ :

$\beta_{\mathrm{df}}=\beta_{\mathrm{nd}+\mathrm{df}} \frac{\left(\delta_{\mathrm{dn}+\mathrm{df}}-\delta_{\mathrm{nd}}\right)\left(1+\delta_{\mathrm{df}}\right)}{\left(\delta_{\mathrm{df}}-\delta_{\mathrm{nd}}\right)\left(1+\delta_{\mathrm{dn}+\mathrm{df}}\right)}$ for $\delta_{\mathrm{nd}+\mathrm{df}}>\delta_{\mathrm{nd}}$,

$\beta_{\mathrm{df}}=0$ for $\delta_{\text {nd }+\mathrm{df}} \leq \delta_{\text {nd }}$,

$\beta_{\mathrm{nd}}=\beta_{\mathrm{nd}+\mathrm{df}}-\beta_{\mathrm{df}}$,

with the backscatter coefficient $\beta_{\text {nd+df }}$ (Eq. 8) for the mixture of non-dust and fine-dust particles; the respective linear depolarization ratio $\delta_{\mathrm{dn}+\mathrm{df}}$ (Eqs. 9 and 10); the fine dust depolarization ratio $\delta_{\mathrm{df}}=0.16$ for $532 \mathrm{~nm}, 0.21$ for $355 \mathrm{~nm}$, and 0.09 for $1064 \mathrm{~nm}$ according to Table 1; and the non-dust depolarization ratio $\delta_{\mathrm{nd}}=0.05$.

\subsection{Dust and non-dust extinction coefficients}

Height profiles of the dust extinction coefficients $\sigma_{\mathrm{d}}, \sigma_{\mathrm{df}}$, and $\sigma_{\mathrm{dc}}$ are obtained by multiplying the backscatter coefficients $\beta_{\mathrm{d}}, \beta_{\mathrm{df}}$, and $\beta_{\mathrm{dc}}$ with respective lidar ratios, e.g., with $S_{\mathrm{d}}=55 \mathrm{sr}$ for western Saharan dust at 355 and $532 \mathrm{~nm}$ (Tesche et al., 2009b, 2011a; Groß et al., 2011, 2015) and about 35-45 sr for eastern Saharan, Middle Eastern, and central Asian dust (Mamouri et al., 2013; Nisantzi et al., 2015; Hofer et al., 2017). If the non-dust aerosol component is of marine origin, as over Barbados during the summer season, we use a typical lidar ratio of $S_{\mathrm{m}}=20 \mathrm{sr}$ for marine particles at 355 and $532 \mathrm{~nm}$ (Groß et al., 2011; Rittmeister et al., 2017; Haarig et al., 2017b) and a slightly higher value of $25 \mathrm{sr}$ for $1064 \mathrm{~nm}$ to obtain the marine particle extinction coefficient $\sigma_{\mathrm{m}}$. If the non-dust aerosol is of continental (anthropogenic) origin, a reasonable lidar ratio would be $S_{\mathrm{c}}=50 \mathrm{sr}$ (at $532 \mathrm{~nm}$ ) and $60-70 \mathrm{sr}$ (at $355 \mathrm{~nm}$ ) in the estimation of the extinction coefficient of anthropogenic aerosols $\sigma_{\mathrm{c}}$. In the case of lofted layers in the free troposphere with aged mixtures of dust and aerosol pollution (haze, smoke), the conversion of the backscatter into extinction profile may be complicated by the fact that the non-dust particles may grow during long-range transport (Müller et al., 2007) and respective changes in the non-dust lidar ratios cannot be excluded (Rittmeister et al., 2017).

For $1064 \mathrm{~nm}$, directly observed particle lidar ratios for anthropogenic haze, biomass-burning smoke, mineral dust, and marine aerosols are not available. We can estimate them from combined lidar-photometer observations during aerosol conditions in which one of these aerosol components dominates the column optical properties. The lidar delivers the vertically integrated backscatter coefficient (column backscatter) and the AERONET photometer yields the $1020 \mathrm{~nm}$ AOT. By using the wavelength dependence between the AOT values at 870 and $1020 \mathrm{~nm}$, we may estimate the $1064 \mathrm{~nm}$ AOT by extrapolation. Finally, the ratio of the $1064 \mathrm{~nm}$ AOT and the $1064 \mathrm{~nm}$ column backscatter value provides an experimentally determined column lidar ratio. An example of the retrieval of the $1064 \mathrm{~nm}$ dust lidar ratio is given in Sect. 6. Lidar ratios for 532 and $1064 \mathrm{~nm}$ for all main aerosol types can also be found in Omar et al. (2009).

\subsection{Non-dust aerosol type}

In case that the polarization lidar is equipped with a nitrogen Raman channel (at 387 and/or $607 \mathrm{~nm}$ ) so that height profiles of the particle extinction coefficient at 355 and $532 \mathrm{~nm}$ can be determined (Rittmeister et al., 2017; Haarig et al., 2017a), we have the potential to evaluate whether the non-dust aerosol component is of marine or anthropogenic origin or even a mixture of both. The Raman lidar yields the particle extinction coefficient:

$\sigma_{\mathrm{p}}=\sigma_{\mathrm{d}}+\sigma_{\mathrm{m}}+\sigma_{\mathrm{c}}$.

Similarly, the POLIPHON method delivers estimates of the particle extinction coefficient by means of the following equation:

$\sigma_{\mathrm{p}}=S_{\mathrm{d}} \beta_{\mathrm{d}}+f_{\mathrm{m}} S_{\mathrm{m}} \beta_{\mathrm{nd}}+f_{\mathrm{c}} S_{\mathrm{c}} \beta_{\mathrm{nd}}$.

$f_{\mathrm{m}}$ and $f_{\mathrm{c}}$ denote the relative contributions of marine and continental anthropogenic aerosol particles to the non-dust

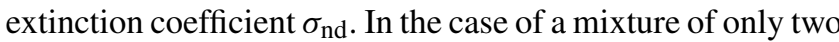
components (dust and smoke with $f_{\mathrm{c}}=1$ and $f_{\mathrm{m}}=0$ or dust and marine with $f_{\mathrm{c}}=0$ and $f_{\mathrm{m}}=1$ ), we can check whether the residual component is of marine or continental origin by comparing the Raman lidar extinction coefficient profiles (Eq. 14) and the POLIPHON extinction profiles (Eq. 15). In Sect. 6, the best match of both extinction profiles is obtained for the Barbados lidar observations for $f_{\mathrm{c}}=0$, i.e., for the mixture of dust and marine particles. Ansmann et al. (2017) 
report an observation with a mixture of dust and marine particles in the lower part of the SAL and a mixture of dust and smoke in the upper part of the SAL. The measurement was performed with a shipborne lidar (as part of SALTRACE) over the tropical Atlantic between Barbados and Cabo Verde during the final phase of the burning season in Africa in May 2013.

\subsection{Dust and non-dust particle mass concentrations}

In the final step, the set of obtained particle backscatter and extinction coefficients is converted into particle volume concentration and, by applying appropriate values for particle density, into mass concentrations. The mass concentrations $M_{\mathrm{df}}, M_{\mathrm{dc}}$, and $M_{\mathrm{nd}}$ for fine dust, coarse dust, and non-dust particles (i.e., $M_{\mathrm{m}}, M_{\mathrm{c}}$ ), respectively, can be obtained by using the following relationships (Ansmann et al., 2011a, 2012; Mamouri and Ansmann, 2014):

$M_{\mathrm{d}}=\rho_{\mathrm{d}} c_{\mathrm{v}, \mathrm{d}, \lambda} \beta_{\mathrm{d}, \lambda} S_{\mathrm{d}, \lambda}$,

$M_{\mathrm{df}}=\rho_{\mathrm{d}} c_{\mathrm{v}, \mathrm{df}, \lambda} \beta_{\mathrm{df}, \lambda} S_{\mathrm{df}, \lambda}$,

$M_{\mathrm{dc}}=\rho_{\mathrm{d}} c_{\mathrm{v}, \mathrm{dc}, \lambda} \beta_{\mathrm{dc}, \lambda} S_{\mathrm{dc}, \lambda}$,

$M_{\mathrm{c}}=\rho_{\mathrm{c}} c_{\mathrm{v}, \mathrm{c}, \lambda} \beta_{\mathrm{c}, \lambda} S_{\mathrm{c}, \lambda}$,

$M_{\mathrm{m}}=\rho_{\mathrm{m}} c_{\mathrm{v}, \mathrm{m}, \lambda} \beta_{\mathrm{m}, \lambda} S_{\mathrm{m}, \lambda}$.

The particle densities $\rho_{\mathrm{d}}, \rho_{\mathrm{c}}$, and $\rho_{\mathrm{m}}$ for dust, continental aerosol pollution, and marine particles are assumed to be 2.6, 1.55 , and $1.1 \mathrm{~g} \mathrm{~cm}^{-3}$, respectively (Ansmann et al., 2012).

The extinction-to-volume conversion factors $c_{\mathrm{v}, i, \lambda}$ applied to convert particle extinction coefficients into particle volume concentrations are listed in Tables 2 and 3 and studied in detail in Sect. 5. The overall uncertainties in all retrievals will be discussed in Sect. 4.7. Standard deviations of all conversion parameters in Tables 2 and 3 are the basic information in the uncertainty analysis.

During SALTRACE-3 the $340 \mathrm{~nm}$ channel of the AERONET photometer was not working properly, so that we provide the respective values for $380 \mathrm{~nm}$ in Table 2 . For Cabo Verde and Barbados we computed the fine dust conversion factors $c_{\mathrm{v}, \mathrm{df}, \lambda}$ at $1064 \mathrm{~nm}$ from cases with finemode $1064 \mathrm{~nm}$ AOT $>0.03$, and for Cyprus we considered observations with fine-mode $1064 \mathrm{~nm}$ AOT $>0.05$ only in the calculations of $c_{\mathrm{v}, \mathrm{df}, \lambda}$ at $1064 \mathrm{~nm}$. Otherwise, a strong impact of AERONET retrieval uncertainties become visible in our statistics. The values in Table 3 for anthropogenic haze and smoke are based on long-term observations in Cyprus (eastern Mediterranean) and Germany (central Europe). Only observations with Ångström exponent, AE $(440-870 \mathrm{~nm})>1.6$, are used and interpreted as continental-aerosol-dominated cases. More details are given in Sect. 5.

\subsection{Consistency between one-step and two-step retrieval products}

In Sect. 6, we will apply both the one-step and the two-step method to demonstrate that the entire POLIPHON concept is consistent, i.e., that the results obtained with both methods agree in terms of the profiles of the non-dust and total dust backscatter coefficients. Such a consistency analysis is a necessary proof of the overall retrieval concept but has not been presented in our previous article (Mamouri and Ansmann, 2014).

By using the characteristic depolarization ratios in Table 1 and thus well-defined values for $\delta_{\mathrm{d}}$ and $\delta_{\text {nd }}$ in the one-step method and $\delta_{\mathrm{df}}, \delta_{\mathrm{dc}} \mathrm{n}$ and $\delta_{\mathrm{nd}}$ in the two-step method, the only degree of freedom is the input profile of $\delta_{\text {nd }+d f}$, i.e., the height profile of the depolarization ratio for the mixture of non-dust and fine-dust particles. We can find the optimum value for $\delta_{\text {nd }+ \text { df }}$ by varying this input parameter (for a given height level) in the two-step data analysis until both solutions for the total dust backscatter coefficient, calculated with the one-step and the two-step method, agree. We repeat this procedure for each height level and obtain in this way the profile $\delta_{\text {nd }+ \text { df }}$. In Sect. 6, we will present an example of this procedure. Such a consistency check can best be performed at vertically homogeneous dust conditions, i.e., when the particle size distribution characteristics and corresponding fine dust and coarse dust fractions in the analyzed dust layer are almost height-independent, as was the case over Barbados during the SALTRACE summer campaigns as the aircraft and lidar observations indicate (Gasteiger et al., 2017).

\subsection{Retrieval uncertainties}

Uncertainties in the basic lidar-derived optical properties and the POLIPHON retrieval products are extensively analyzed and discussed by Freudenthaler et al. (2009), Tesche et al. (2009b, 2011a, b), Mamouri et al. (2013), Mamouri and Ansmann $(2014,2016)$, and Bravo-Aranda et al. (2016) and will not be discussed here. Typical uncertainties in the basic particle optical properties are given in Table 4 for $532 \mathrm{~nm}$. The uncertainties for $1064 \mathrm{~nm}$ are similar. However, in the case of the very uncertain $355 \mathrm{~nm}$ particle depolarization obtained with BERTHA (Haarig et al., 2017a) during SALTRACE, the errors may be at all a factor of 2 higher for the $355 \mathrm{~nm}$ POLIPHON products in Sect. 6. Uncertainties in the derived mass concentrations, also given in Table 4, result from the uncertainties in the backscatter separation (as a function of the uncertainties in the input parameters), in the particle extinction coefficients, in the extinction-to-volume conversion factors (Tables 2 and 3), and in the assumed particle densities.

Haarig et al. (2017b) point to another (new) uncertainty source in case that marine particles get mixed into layers with low relative humidity (RH). As long as RH is above 50-60\% the particle depolarization ratio of the dried marine particles 
Table 2. Extinction-to-volume conversion factors for desert dust required in Eqs. (16)-(18) in Sect. 4.5. The listed mean values of $c_{\mathrm{V}, i, \lambda}$ (in $10^{-12} \mathrm{Mm}$ ) and SD are computed from averaging of all individual dust observations of these conversion factors of carefully filtered AERONET dust data sets (Cabo Verde and Barbados, Limassol, Cyprus). See the text in Sects. 4.5 and 5 for more details.

\begin{tabular}{lccc}
\hline Desert dust & $c_{\mathrm{v}, \mathrm{d}, \lambda}$ & $c_{\mathrm{v}, \mathrm{df}, \lambda}$ & $c_{\mathrm{v}, \mathrm{dc}, \lambda}$ \\
\hline Cabo Verde, Barbados, 355-380 nm & $0.62 \pm 0.05$ & $0.15 \pm 0.02$ & $0.86 \pm 0.05$ \\
Cabo Verde, Barbados, 532 nm & $0.64 \pm 0.06$ & $0.21 \pm 0.04$ & $0.79 \pm 0.07$ \\
Cabo Verde, Barbados, 1064 nm & $0.73 \pm 0.06$ & $0.63 \pm 0.13$ & $0.72 \pm 0.04$ \\
Cyprus, 355 nm & $0.54 \pm 0.08$ & $0.15 \pm 0.04$ & $0.86 \pm 0.08$ \\
Cyprus, 532 nm & $0.61 \pm 0.06$ & $0.25 \pm 0.05$ & $0.79 \pm 0.08$ \\
Cyprus, 1064 nm & $0.76 \pm 0.07$ & $0.61 \pm 0.20$ & $0.71 \pm 0.07$ \\
\hline
\end{tabular}

Table 3. Extinction-to-volume conversion factors for non-dust components (continental aerosol pollution, marine aerosol) required in Eqs. (19)-(20) in Sect. 4.5. The listed mean values of $c_{\mathrm{v}, i, \lambda}$ (in $10^{-12} \mathrm{Mm}$ ) and SD are computed from averaging of all individual marine or aerosol pollution observations of these conversion factors of carefully filtered marine and aerosol pollution AERONET data sets (marine: Ragged Point, Barbados; aerosol pollution: Leipzig, Germany, and Limassol, Cyprus). See the text in Sects. 4.5 and 5 for more details.

\begin{tabular}{lc}
\hline Continental aerosol & $c_{\mathrm{v}, \mathrm{c}, \lambda}$ \\
\hline Cyprus, $355 \mathrm{~nm}$ & $0.23 \pm 0.04$ \\
Cyprus, 532 nm & $0.41 \pm 0.07$ \\
Cyprus, $1064 \mathrm{~nm}$ & $1.41 \pm 0.32$ \\
Germany, $355 \mathrm{~nm}$ & $0.17 \pm 0.04$ \\
Germany, $532 \mathrm{~nm}$ & $0.30 \pm 0.08$ \\
Germany, $1064 \mathrm{~nm}$ & $0.96 \pm 0.34$ \\
\hline Marine aerosol & $c_{\mathrm{v}, \mathrm{m}, \lambda}$ \\
\hline Barbados, 355 nm & $0.53 \pm 0.12$ \\
Barbados, 532 nm & $0.65 \pm 0.14$ \\
Barbados, $1064 \mathrm{~nm}$ & $0.97 \pm 0.20$ \\
\hline
\end{tabular}

is in the range of $0.05 \pm 0.02$ and is thus well enough covered by our assumption that non-dust aerosol causes a depolarization ratio of 0.05 or lower. However, if $\mathrm{RH}$ is $40 \%$ or even $20-30 \%$ in the SAL and marine particles get mixed into this layer, they dry completely and can cause depolarization ratios on the order of 0.15 at $532 \mathrm{~nm}$ and about 0.1 at 355 and $1064 \mathrm{~nm}$. This may then be misinterpreted as contribution by dust particles. However, as long as the marine particle fraction (contribution to backscattering) in the SAL is low, as during SALTRACE, this effect is negligible.

\section{Extinction-to-volume conversion factors from AERONET}

Trustworthy extinction-to-volume conversion factors $c_{\mathrm{v}, i, \lambda}$ in Eqs. (16)-(20) are of key importance for an accurate retrieval of mass concentration profiles from lidar data (Ansmann et al., 2012; Mamouri and Ansmann, 2014). We de- termined these conversion factors from extensive correlation studies between the AOT and column-integrated particle volume concentrations obtained from long-term AERONET observations at Limassol (Cyprus), Leipzig (Germany), Ragged Point (Barbados) and the mentioned short-term SAMUM and SALTRACE field campaigns (AERONET, 2016). The results are shown in this section. More details of our AERONET data analysis can be found in Mamouri and Ansmann (2016).

AERONET-based correlation studies regarding the link between optical and microphysical aerosol properties were already presented in previous studies (Ansmann et al., 2011a, 2012). However, these studies were performed by using few carefully selected AERONET observations (on the order of 5-20 cases) and covered only dust outbreak and urban haze situations. In previous papers we calculated coarse-moderelated conversion factors during dust outbreak situations and fine-mode-related conversion factors during urban haze conditions and applied them to lidar measurements of desertdust/urban haze mixtures to separate the dust fraction and haze fraction.

Our recent analysis is based on 48474 and 34982 sun/sky photometer observation taken at Limassol and Leipzig, respectively. From these large data sets, we selected 421 Limassol and 974 Leipzig quality-assured data sets for the aerosol type of continental anthropogenic pollution (Ångström exponent $\mathrm{AE}>1.6$ for the $440-870 \mathrm{~nm}$ wavelength range). The Ångström exponent (Ångström, 1964) describes the wavelength dependence of AOT. Low values $(<0.5)$ indicated coarse-mode-dominated aerosol conditions and are thus indicative for dust outbreaks, whereas high values ( $>1.6)$ occur during situations with dominating finemode aerosol pollution.

We selected 116 AERONET observations with strong desert dust outbreaks and optically dense dust layers in Morocco (SAMUM-1), Cabo Verde (SAMUM-2), and Barbados (SALTRACE). We analyzed the Limassol AERONET observations for dusty conditions as well. This dust data set comprises 122 observations with $500 \mathrm{~nm}$ AOT $>0.1$ and $\mathrm{AE}<0.5$. From the 2007-2015 Ragged Point AERONET observations we selected 123 observations of pure ma- 
Table 4. Typical uncertainties in the lidar-derived particle optical properties (for $532 \mathrm{~nm}$ wavelength), and volume and mass concentrations. MBL stands for marine boundary layer.

\begin{tabular}{llr}
\hline Parameter & & Relative uncertainty \\
\hline Backscatter coefficient & $\beta_{\mathrm{p}}$ & $5-10 \%$ \\
Backscatter coefficient (desert dust) & $\beta_{\mathrm{d}}$ & $10-15 \%$ \\
Backscatter coefficient (continental) & $\beta_{\mathrm{c}}$ & $10-20 \%$ \\
Backscatter coefficient (marine) & $\beta_{\mathrm{m}}$ & $20 \%(\mathrm{MBL})$ \\
Extinction coefficient (desert dust) & $\sigma_{\mathrm{d}}, \sigma_{\mathrm{df}}, \sigma_{\mathrm{dc}}$ & $15-25 \%, 30-50 \%, 20-30 \%$ \\
Extinction coefficient (continental) & $\sigma_{\mathrm{c}}$ & $20-30 \%$ \\
Extinction coefficient (marine) & $\sigma_{\mathrm{m}}$ & $25 \%(\mathrm{MBL})$ \\
Mass concentration (desert dust) & $M_{\mathrm{d}}, M_{\mathrm{df}}, M_{\mathrm{dc}}$ & $20-30 \%, 40-60 \%, 25-35 \%$ \\
Mass concentration (continental) & $M_{\mathrm{c}}$ & $30-35 \%$ \\
Mass concentration (marine) & $M_{\mathrm{m}}$ & $30-40 \%(\mathrm{MBL})$ \\
\hline
\end{tabular}

rine conditions. Clean marine conditions were defined by a $500 \mathrm{~nm}$ AOT $<0.07$ and an Ångström exponent of $<0.7$. We identified nine cases of clean marine conditions in the 4-year Limassol AERONET data sets. Further details of the selection criteria, which were applied to sort the individual observations into desert dust, anthropogenic pollution, and marine aerosol classes, can be found in Mamouri and Ansmann (2016).

In the following regression analysis, we study the correlation between the particle extinction coefficient and the particle volume concentration for the defined aerosol types (marine, dust, continental pollution). We performed the AERONET correlation study also separately for all three laser wavelengths but present the results for the mostly used lidar wavelength of $532 \mathrm{~nm}$ only. As shown in Mamouri and Ansmann (2016), the particle volume concentration $v$ is derived from the respective column volume concentrations and the extinction coefficient $\sigma$ is computed from the available AOT values. Interpolation within the measured AOT spectrum yielded the $\sigma$ values for the laser wavelengths of 355 and $532 \mathrm{~nm}$. The $1064 \mathrm{~nm}$ AOT was computed from the $1020 \mathrm{~nm}$ AOT and the Angström exponent for the 870$1020 \mathrm{~nm}$ spectral range.

The correlations between $v$ and $\sigma$ at $532 \mathrm{~nm}$ based on the desert dust field campaign observations during SAMUM1, SAMUM-2, and SALTRACE and on the long-term data sets collected at Limassol, Cyprus, during dust outbreaks are shown in Fig. 2. A clear linear dependence of the particle volume concentration (fine, coarse, total) on the light extinction coefficient at $532 \mathrm{~nm}$ is given. The variability in the correlated data is very low. A potential impact of boundary layer aerosol (marine particles over Barbados, anthropogenic haze over Limassol) on the correlation (and the determined dust extinction-to-volume conversion factors) is estimated to be on the order of a few percent. Because AERONET observations for low $\mathrm{AE}<0.5$ are considered in Fig. 2 only, the influence of fine-mode aerosol pollution is rather low. The influence of marine particles is small because dust and marine particle size distributions are similar, and thus the corre- lations between volume concentration and extinction coefficient are similar for both aerosol types.

The respective correlation plots for pure marine conditions at Barbados and Cyprus for all three wavelengths are presented in Fig. 3. The scatter in the plotted data is now much larger. Changes in the size distribution and thus in the correlation of $\sigma$ with $v$ are mostly related to changing weather conditions. Wind speed controls the amount of sea salt in the air and the convective activity in the marine boundary layer (MBL) regulates the strength of entrainment of dry air into the MBL from above and thus drying and shrinking of marine particles. Another reason for the observed scatter in the correlated data may be the uncertainties in the AERONET retrieval of the size distribution and volume concentration. The uncertainty is likewise high when the AOT is very low as in the case of pure marine aerosols.

Figure $4 \mathrm{a}$ and $\mathrm{b}$ show the results of the correlations analysis for the long-term observations at Limassol and Leipzig for urban haze scenarios. Only cases with $\mathrm{AE}>1.6$ are considered. The correlation between the particle extinction coefficient and the volume concentration for fine-mode-dominated continental aerosols is comparably high, taking the potential impact of water uptake effects with changing relative humidity conditions, different sources for fine-mode particles, age, and transport ways (short for local and regional aerosol, long for remote sources) into account. Differences in the correlation parameters derived from the Limassol and Leipzig data sets probably result from the fact that Cyprus is an island in the Mediterranean Sea and desert areas are not far away so that the background aerosol always contains some coarse marine and dust particles, whereas Leipzig is located in a densely populated and highly industrialized region of central Europe, far away from sources of marine and desert aerosol particles so that fine-mode aerosol pollution is usually dominating, especially when $\mathrm{AE}>1.6$ as in Fig. 4a. Note that the extinction-to-volume conversion factor increases with increasing mean particle size from about $0.2 \times 10^{-12} \mathrm{Mm}$ for pure fine-mode aerosols to about $0.8 \times 10^{-12} \mathrm{Mm}$ for coarse dust particles. 

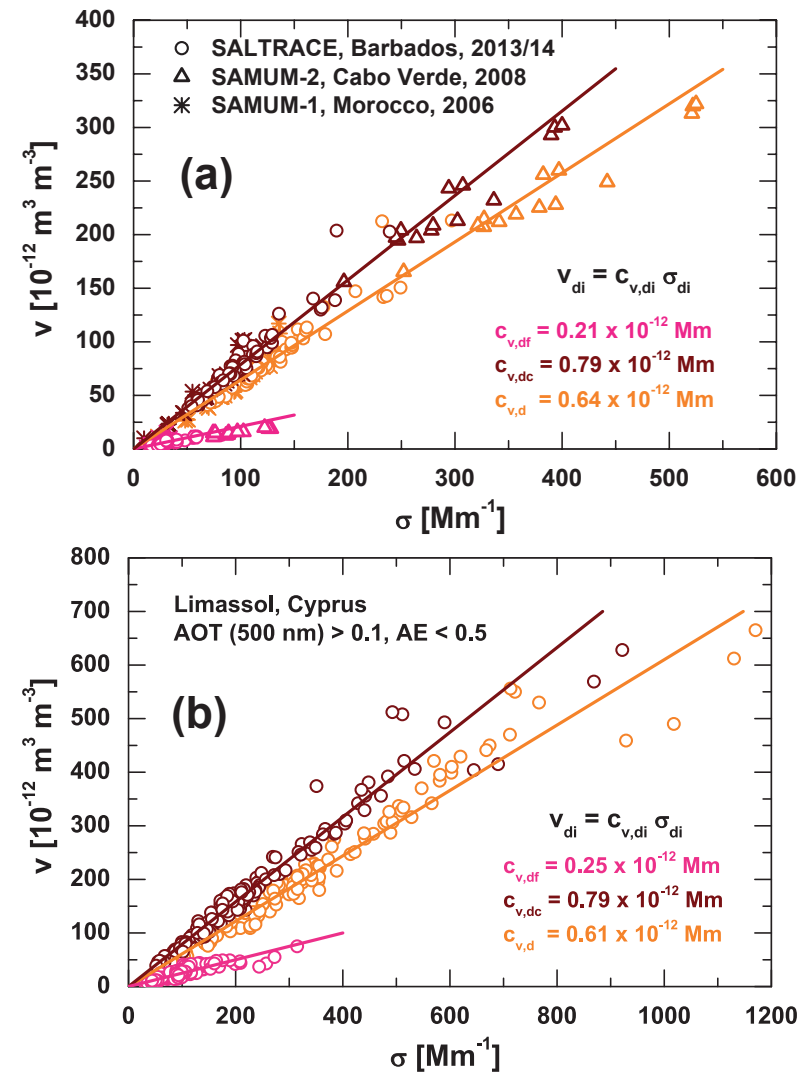

Figure 2. Relationship between the $532 \mathrm{~nm}$ extinction coefficient $\sigma$ and the particle volume concentration $v$ considering (a) only pronounced dust outbreaks (116 observations on 41 days) during the SAMUM and SALTRACE campaigns in Morocco, Cabo Verde, and Barbados and (b) dust events over the AERONET station of Limassol, Cyprus (CUT-TEPAK site, 122 observations on 35 days in the period from July 2011 to June 2015). Correlations are separately shown between the total (orange), fine (pink), and coarse (dark red) dust extinction coefficient $\left(\sigma_{\mathrm{d}}, \sigma_{\mathrm{df}}, \sigma_{\mathrm{dc}}\right)$ and the respective volume concentration $\left(v_{\mathrm{d}}, v_{\mathrm{df}}, v_{\mathrm{dc}}\right)$. The slopes of the lines indicate the mean increase of $v_{\mathrm{d}}, v_{\mathrm{df}}$, and $v_{\mathrm{dc}}$ with the respective $\sigma_{\mathrm{d}}, \sigma_{\mathrm{df}}$, and $\sigma_{\mathrm{dc}}$. The extinction-to-volume conversion factors $c_{\mathrm{v}, \mathrm{d}}, c_{\mathrm{v}, \mathrm{df}}$, and $c_{\mathrm{V}, \mathrm{dc}}$ are given as numbers in panels (a) and (b) and are also listed in Table. 2.

For all individual, single AERONET observations (belonging to a given marine, desert dust, or continental anthropogenic aerosol data set), we calculated $v / \sigma$ ratios for all three laser wavelengths. The mean values of $v_{i} / \sigma(\lambda)$ together and the corresponding standard deviation, SD (obtained from the averaging procedure), for each specific data set are listed in Tables 2 and 3. Because of problems with the AERONET photometer channel at $340 \mathrm{~nm}$ during SAMUM1 as outlined in Mamouri and Ansmann (2016), we consider only Cyprus, Cabo Verde, and Barbados observations in Table 2. Furthermore, only the marine Ragged Point conversion factors are given in Table 3. The Cyprus and Ragged Point marine conversion factors deviate by no more than $1 \%$ (355,

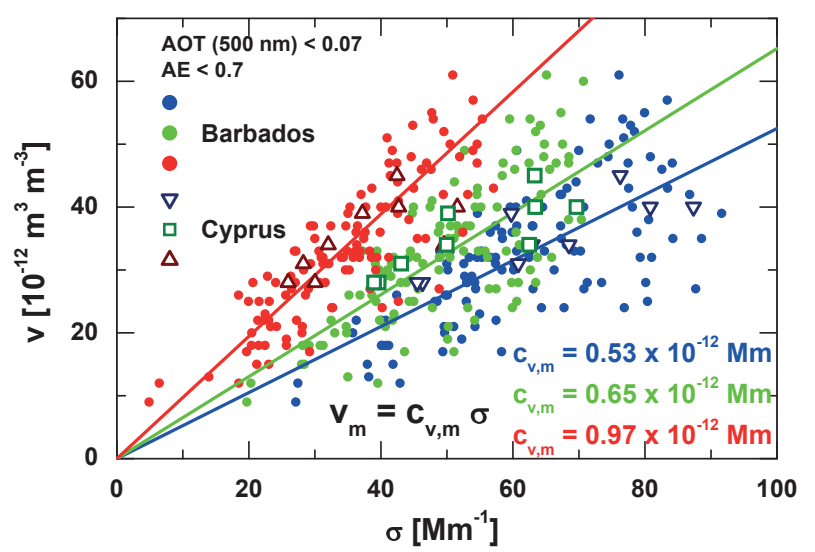

Figure 3. Relationship between particle extinction coefficient $\sigma_{\mathrm{m}}$ and particle volume concentration $v_{\mathrm{m}}$ for pure marine cases measured at the AERONET station of Ragged Point, Barbados (circles; 123 observations on 91 different days in the period from August 2007 to February 2015), and at Limassol (triangles for 355 and $1064 \mathrm{~nm}$, squares for $532 \mathrm{~nm}$; nine observations on 4 different days in the period from July 2011 to June 2015). Correlations are shown for $355 \mathrm{~nm}$ (blue), $532 \mathrm{~nm}$ (green), and $1064 \mathrm{~nm}$ extinction coefficients (red). The slope of the lines indicate the mean increase of $v_{\mathrm{m}}$ with $\sigma_{\mathrm{m}}$ for the Barbados data set. The respective conversion factors $c_{\mathrm{V}, \mathrm{m}}$ for the three laser wavelengths are given as numbers. They are also listed in Table 3.

$532 \mathrm{~nm})$ and $2 \%(1064 \mathrm{~nm})$. The mean values of $v_{i} / \sigma(\lambda)$ of aerosol type $i$ and given wavelength $\lambda$ are used as the conversion factors $c_{\mathrm{v}, i, \lambda}$ in Eqs. (16)-(20). The SD values of coarse and total dust conversion factors are around $10 \%$. For fine dust, marine, and continental aerosol pollution, the SD values of the conversion factors are on the order of $20 \%$.

\section{Case study: SALTRACE observation on 20 June 2014}

The full POLIPHON methodology, outlined in Sect. 4, is applied to a triple-wavelength polarization lidar measurement performed on 20 June 2014 during SALTRACE-3. The results are discussed in this section. The selected SALTRACE3 case is described in detail in Haarig et al. (2017a). A short overview of the basic lidar observations of particle backscatter and depolarization-ratio profiles is given in Sect. 6.1. The solutions of the one-step POLIPHON data analysis separately performed for 355,532 , and $1064 \mathrm{~nm}$ are presented in Sect. 6.2. The results of the two-step method and the use of the one-step method to find the optimum set of solutions for the marine, fine dust, and coarse dust extinction and mass concentration profiles are discussed in the Sect. 6.3. In addition, the consistency between the Raman-lidar-derived total extinction coefficients and the sum of the extinction contributions by dust and non-dust aerosol components is shown in this section. We finally apply the two-step POLIPHON 

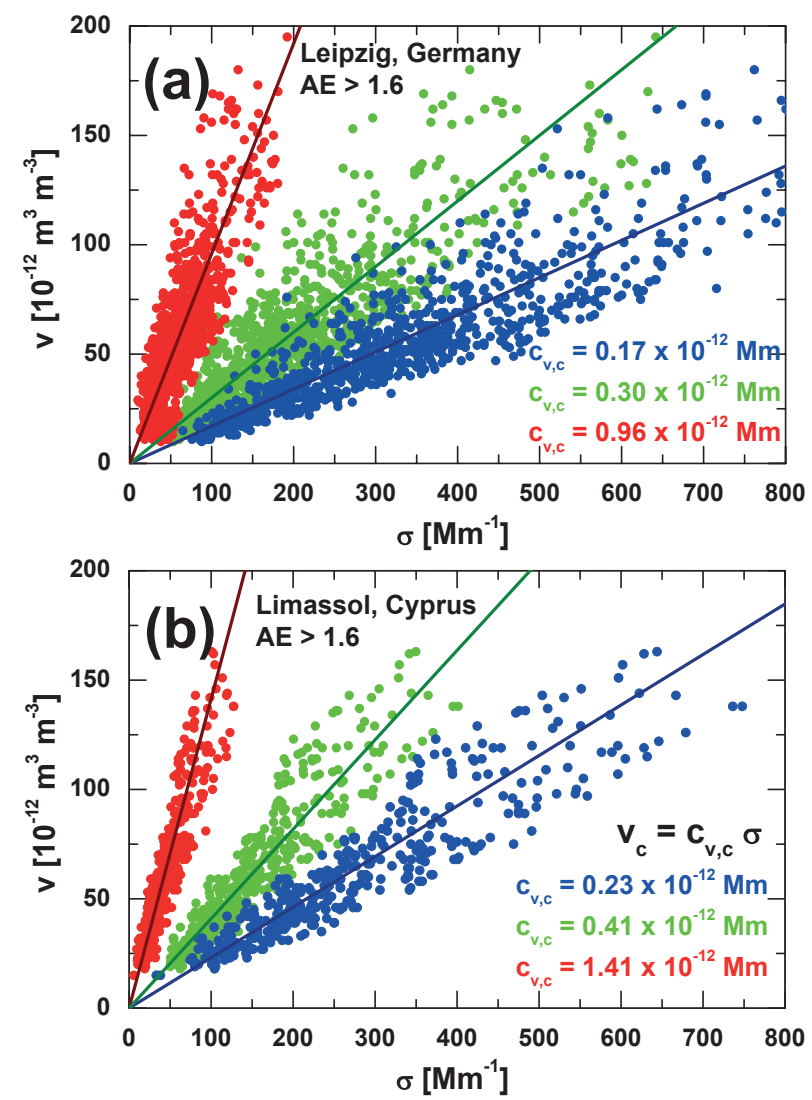

Figure 4. Same as Fig. 3 except for cases dominated by fine-mode aerosol pollution measured at (a) Leipzig (974 observations in the period from May 2001 to June 2015) and (b) Limassol (421 observations in the period from July 2011 to June 2015). Correlations and mean conversion factors are shown for the laser wavelengths of 355 (blue), 532 (green), and $1064 \mathrm{~nm}$ (red). Conversion factors are given as numbers and also listed in Table 3.

method to the polarization lidar measurements at all three wavelengths in Sect. 6.4 and check the consistency between all solutions, and we discuss which of the wavelengths is most robust, i.e., most favorable to separate and retrieve, fine dust, coarse dust, and non-dust aerosol extinction coefficient and mass concentration profiles.

\subsection{Dust layering over Barbados on 20 June 2014}

As shown in Fig. 5, a $3 \mathrm{~km}$ deep Saharan dust layer was observed on 20 June 2014. The radiosonde profile of RH shows a moist MAL with $\mathrm{RH}>75 \%$ up to about $1.2 \mathrm{~km}$ height. Above the MAL, two dust layers were detected between 1.2 and $3 \mathrm{~km}$ height and another layer from 3 to $4 \mathrm{~km}$ height. According to the backward trajectories in Fig. 6, African dust was transported on an almost direct way from western Africa to Barbados. The air mass needed 4-5 days to cross the Atlantic Ocean before reaching the Caribbean. The nondust aerosol within the SAL probably consisted of a mix- ture of marine particles, which entered the SAL during the $4500 \mathrm{~km}$ travel from below during cloud convection periods, and aged African biomass-burning smoke and anthropogenic haze (Rittmeister et al., 2017). The thin dust layer between 3 and $4 \mathrm{~km}$ height crossed Saharan desert regions at heights around $6 \mathrm{~km}$ and thus contained only traces of dust but almost no non-dust aerosol. The lofted dusty air masses showed mostly RH values from 40 to $50 \%$. Cirrus was present between 12 and $13.5 \mathrm{~km}$ height and allowed us to check the quality of the triple-wavelength depolarization ratio observations (for more details see Haarig et al., 2017a).

Figure 7 shows the mean profiles of the particle backscatter coefficient and linear depolarization ratio for all three laser wavelengths for the 3-hour period shown in Fig. 5. The $532 \mathrm{~nm}$ particle depolarization ratio ranges from 0.25 to 0.27 below $2.4 \mathrm{~km}$ height and increases almost steadily from 0.25 at $2 \mathrm{~km}$ to $0.28-0.29$ at the top of the SAL at $4 \mathrm{~km}$ height. The particle depolarization ratios at 355 and $1064 \mathrm{~nm}$ are lower with values from 0.22 to 0.26 and roughly heightindependent above $2 \mathrm{~km}$ height. The smaller $1064 \mathrm{~nm}$ depolarization ratios in the uppermost layer may indicate, on average, smaller coarse-mode particles than in the main dust layer below $3 \mathrm{~km}$ height.

In the MAL, all depolarization ratios strongly decrease from values close to 0.25 at $1300 \mathrm{~m}$ height to $<0.1$ at heights below $500 \mathrm{~m}$ above ground. These depolarization ratio values are still significantly above the marine level of $0.02-0.03$ (Groß et al., 2011; Rittmeister et al., 2017; Haarig et al., 2017b) and indicate significant downward mixing of dust over the island of Barbados.

The slightly enhanced depolarization ratios at the top of the MAL (at 1200-1300 m height, RH decreased from 75 of $50 \%$ ) may be partly caused by dried marine sea salt particles (Haarig et al., 2017b). However, the non-dust backscatter fraction above the MAL was on the order of $10 \%$ as will be shown below. In the following we ignore this potential minor influence of sea salt on the depolarization ratio measurement.

\subsection{One-step POLIPHON method}

Figure 8 shows the dust extinction and mass concentration profiles obtained with the traditional dust/non-dust separation technique presented in Sect. 4.1. The one-step retrieval method is applied separately to the lidar observations at 355 , 532 , and $1064 \mathrm{~nm}$. The lidar ratio profiles for 355 and $532 \mathrm{~nm}$ obtained by applying the Raman lidar method indicate typical western Saharan dust values from 50 to $60 \mathrm{sr}$ in the upper dust layer from 3 to $4 \mathrm{~km}$ height and the upper part of the lower dust layer (Tesche et al., 2009b, 2011a; Groß et al., 2011; Haarig et al., 2017a; Rittmeister et al., 2017). Below about $2.5 \mathrm{~km}$ height, the lidar ratios decrease to values around $40 \mathrm{sr}(355 \mathrm{~nm})$ and $45 \mathrm{sr}(532 \mathrm{~nm})$ within the SAL. In the same height range, the non-dust contribution to particle backscattering is on the order of $15-20 \%$. A reduction of 


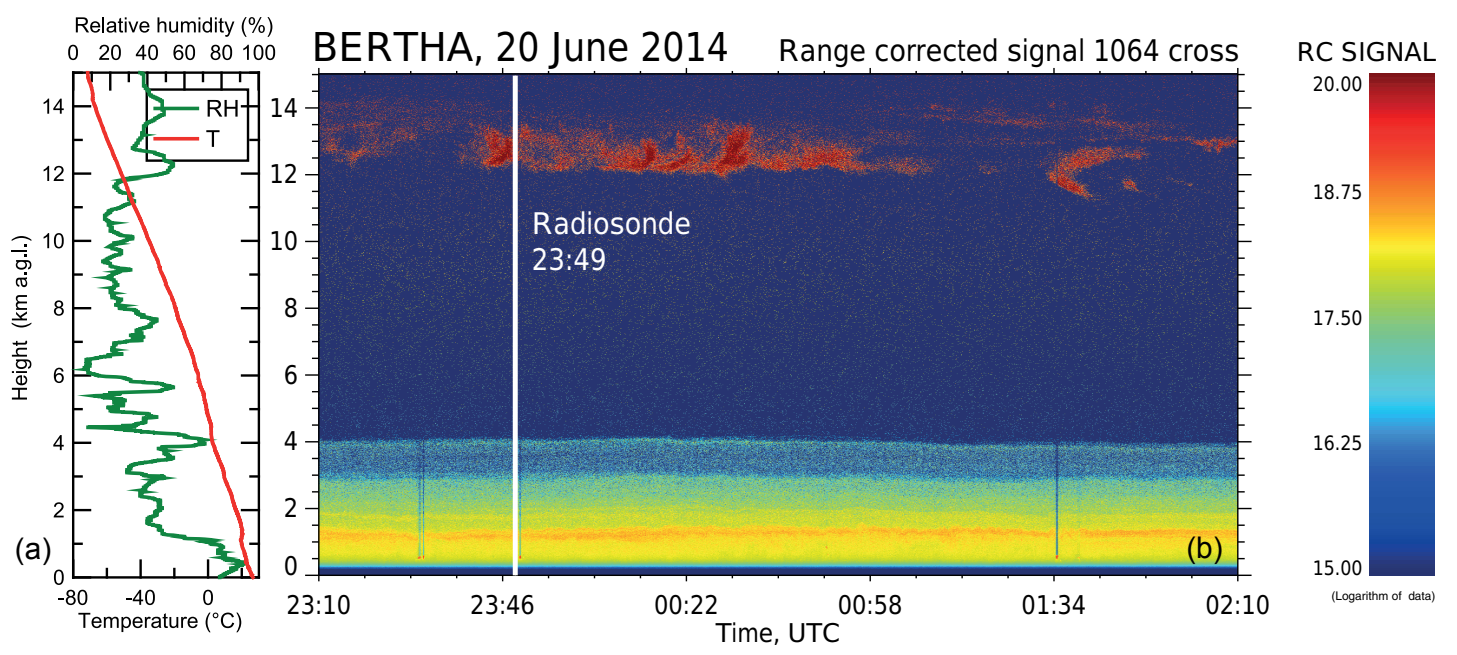

Figure 5. Desert dust layering over Barbados on 20 June 2014 (19:10-22:10 local time) during SALTRACE-3. The range-corrected crosspolarized $1064 \mathrm{~nm}$ lidar return signal is shown. Different dust layers are visible up to $4 \mathrm{~km}$ height. Highly depolarizing ice clouds were present between 12 and $14 \mathrm{~km}$ height. The cirrus layer was used to check the quality of the triple-wavelength depolarization ratio observations (Haarig et al., 2017a). (a) Radiosonde profiles of relative humidity (RH, green) and temperature ( $T$, red). The radiosonde was launched at 23:49 UTC (indicated by a vertical white line in $\mathbf{b}$ ).

NOAA HYSPLIT MODEL Backward trajectories ending at 01:00 UTC 21 Jun 14 GDAS meteorological data

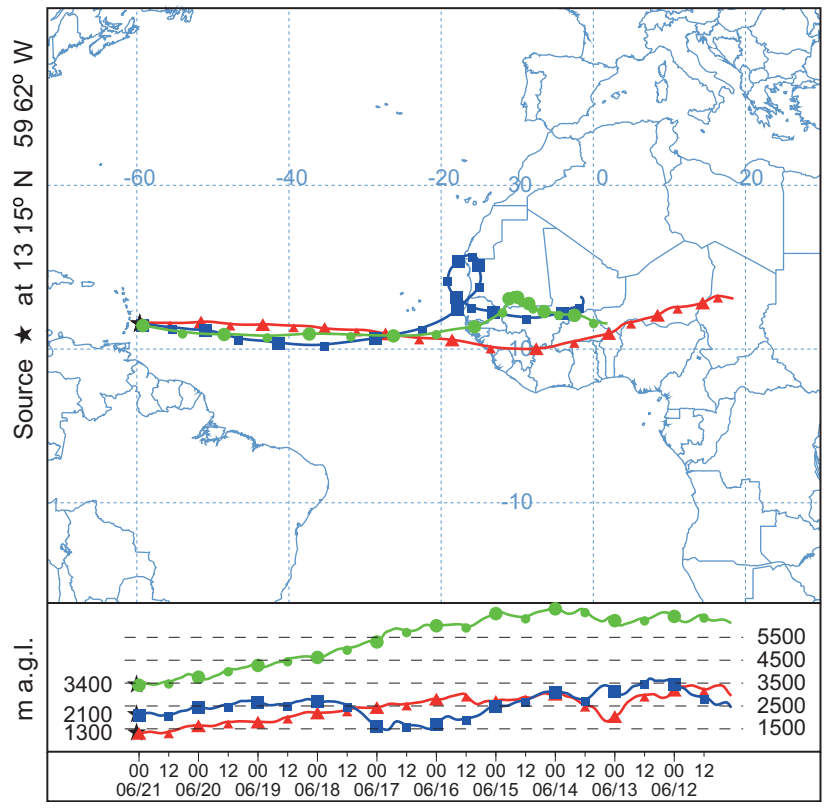

Figure 6. Ten-day HYSPLIT backward trajectories for 21 June 2014, 01:00 UTC (HYSPLIT, 2016). The observed dust left the African continent 4-5 days before arrival over Barbados. Indicated arrival heights are $1.3 \mathrm{~km}$ (red), $2.1 \mathrm{~km}$ (blue), and $3.4 \mathrm{~km}$ (green). the $532 \mathrm{~nm}$ lidar ratio from dust values around 55 sr by about $10 \mathrm{sr}$ points to marine aerosols (lidar ratios of $15-25 \mathrm{sr}$ ) as the main non-dust component. Minor contributions to particle backscattering by aged smoke and haze from Africa can not be excluded.

We used Eqs. (1)-(4) in Sect. 4.1 to separate the dust and non-dust backscatter coefficients. For all three wavelengths, we assumed that non-dust particles cause a depolarization ratio $\leq 0.05$ and pure dust is indicated when the particle depolarization ratio exceeds $0.25(355 \mathrm{~nm}), 0.31(532 \mathrm{~nm})$, and $0.27(1064 \mathrm{~nm})$. The obtained dust backscatter coefficients were then multiplied with lidar ratios of $55 \mathrm{sr}$ (355 and $532 \mathrm{~nm})$ and $67 \mathrm{sr}(1064 \mathrm{~nm})$ to obtain the respective dust extinction coefficients shown in Fig. 8c.

The dust lidar ratio at $1064 \mathrm{~nm}$ was estimated from the AERONET observations of the $1020 \mathrm{~nm}$ AOT shortly before sunset and the column dust backscatter coefficients at $1064 \mathrm{~nm}$ shortly measured after sun set. The AOT was $0.47-0.53(1020-1064 \mathrm{~nm}), 0.50-0.55(500-532 \mathrm{~nm})$, and $0.51-0.56(340-380 \mathrm{~nm})$. After subtracting a typical marine AOT of $0.06(355 \mathrm{~nm}), 0.05(532 \mathrm{~nm})$, and $0.035(1064 \mathrm{~nm})$, we obtained dust-related AOTs of 0.43-0.49 $(1064 \mathrm{~nm})$ and $0.45-0.5$ (355 and $532 \mathrm{~nm}$ ). The AOT fine-mode fractions were $0.28,0.2$, and 0.06 for 355,532 , and $1064 \mathrm{~nm}$, respectively, on the late afternoon of 20 June 2014. In the further estimation of the $1064 \mathrm{~nm}$ dust lidar ratio we considered slight changes in the column backscatter values from before to after sun set as indicated by the continuous lidar observations and assumed that the same changes hold for the $1020 \mathrm{~nm}$ AOT. In this way we estimated the $1064 \mathrm{~nm}$ dust lidar ratio (ratio of $1020 \mathrm{~nm}$ dust-related AOT to $1064 \mathrm{~nm}$ column dust backscatter) to be close to $67 \mathrm{sr}$, and, for consistency, 


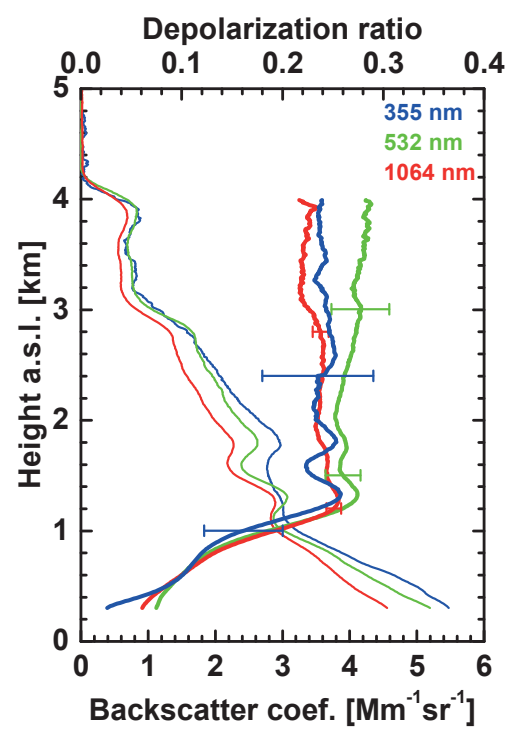

Figure 7. Triple-wavelength particle depolarization ratio profiling on 20 June 2014 during SALTRACE-3. Mean profiles of the particle backscatter coefficient (thin lines) and the particle linear depolarization ratio (thick lines) at $355 \mathrm{~nm}$ (blue), $532 \mathrm{~nm}$ (green), and $1064 \mathrm{~nm}$ (red) wavelength are shown. All signals of the $3 \mathrm{~h}$ period in Fig. 5 are averaged and vertically smoothed with $200 \mathrm{~m}$ window length except in the case of the $355 \mathrm{~nm}$ depolarization ratio above $2.4 \mathrm{~km}$ height. Here, the signal smoothing length is $750 \mathrm{~m}$ (from 2.4 to $3.2 \mathrm{~m}$ height) and $1200 \mathrm{~m}(3.2-4.0 \mathrm{~km}$ height). Error bars indicate retrieval uncertainties in the depolarization ratio values (Haarig et al., 2017a). Relative errors of the particle backscatter coefficients are on the order of $5-10 \%$.

we found a column dust lidar ratio of $55 \mathrm{sr}$ for the 500 $532 \mathrm{~nm}$ wavelength range by using the $500 \mathrm{~nm}$ dust-related AOT from AERONET and the column dust backscatter coefficient at $532 \mathrm{~nm}$ from lidar.

In this dust case, observed on 20 June 2014, the dust-extinction-related Ångström exponent $\left(\mathrm{AE}_{\sigma}, 532-\right.$ $1064 \mathrm{~nm}$ spectral range) was close to 0.15 , the respective backscatter-related Ångström exponent $\left(\mathrm{AE}_{\beta}\right)$ around 0.45 , and the lidar-ratio-related Ångström exponent $\left(\mathrm{AE}_{\mathrm{S}}=\right.$ $\ln (55 / 67) / \ln (1064 / 532))-0.3$. According to Ansmann et al. (2002), $\mathrm{AE}_{\sigma}=\mathrm{AE}_{\beta}+\mathrm{AE}_{\mathrm{S}}$. Thus, a perfect agreement regarding the relationship between the three lidar-derived Angström exponents was obtained from the combined lidarphotometer data analysis.

Finally, the dust mass concentration profiles were calculated with Eq. (16) and the conversion factors in Table 2 (Cabo Verde, Barbados). The result is shown in Fig. 8d. The range of solutions $(355-1064 \mathrm{~nm})$ for the extinction coefficient and mass concentrations in Figs 8c and d reflects well the uncertainties listed in Table 4. However, the uncertainty in the $355 \mathrm{~nm}$ particle depolarization ratios are very large and thus the $355 \mathrm{~nm}$ POLIPHON products in general have to be exercised with care. The strong positive deviations of the mass concentrations derived from the $1064 \mathrm{~nm}$ polariza-

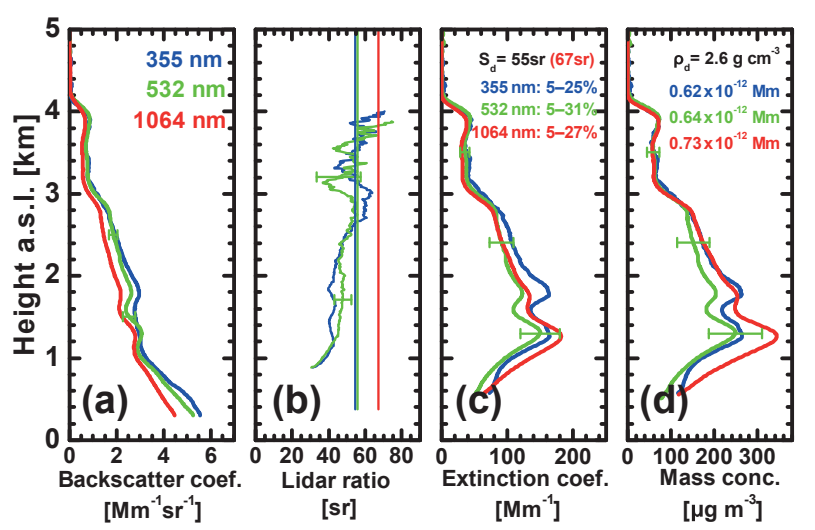

Figure 8. Dust extinction and mass concentration profiles (panels c and d) obtained by applying the one-step POLIPHON method to triple-wavelength polarization lidar observations. (a) Measured particle backscatter coefficients (as in Fig. 7), (b) Raman-lidarderived extinction-to-backscatter ratios $(355 \mathrm{~nm}$ in blue, $532 \mathrm{~nm}$ in green) for the $3 \mathrm{~h}$ period in Fig. 5, (c) derived dust (only) extinction coefficients, and (d) dust mass concentrations. In the one-step POLIPHON data analysis (Sect. 4.1) we used characteristic nondust $(5 \%)$ and dust depolarization ratios $(25,31$, and $27 \%$; also given as numbers in panel c). The dust extinction coefficients are obtained by multiplying the dust backscatter coefficients with a lidar ratio of $55 \mathrm{sr}(355,532 \mathrm{~nm})$ and $67 \mathrm{sr}(1064 \mathrm{~nm})$; see vertical lines in panel (b). The dust extinction coefficients are converted to mass concentrations by means of the conversion factors in Table 2, given as numbers in panel (d). We assume a dust particle mass density of $2.6 \mathrm{~g} \mathrm{~cm}^{-3}$. Error bars show estimated overall retrieval uncertainties of 20 (extinction coefficient) and $25 \%$ (mass concentration) for $532 \mathrm{~nm}$.

tion lidar measurements compared to the respective profiles from the $532 \mathrm{~nm}$ polarization lidar observations are caused by the used conversion factor of $0.73 \times 10^{-12} \mathrm{Mm}$. The actual $1064 \mathrm{~nm}$ conversion factor (for this day) was close to $0.65 \times 10^{-12} \mathrm{Mm}$ as the AERONET observations showed.

\subsection{Two-step POLIPHON method}

We begin the discussion of the two-step method with the approach suggest by Mamouri and Ansmann (2014). The respective results for $532 \mathrm{~nm}$ are shown in Fig. 9. A fixed set of input values for $\delta_{\mathrm{df}}, \delta_{\mathrm{dc}}$, and $\delta_{\mathrm{nd}+\mathrm{df}, \mathrm{e}}$ was used in the data analysis of the 20 June 2014 case. Besides the characteristic particle depolarization ratio for fine dust (0.16), coarse dust (0.39), and non-dust aerosol (0.05), a height-independent depolarization ratio $\delta_{\mathrm{nd}+\mathrm{df}, \mathrm{e}}$ of 0.12 is assumed in the retrieval. This value of 0.12 corresponds to a backscatter contribution of $33 \%$ by non-dust particles and $67 \%$ by fine dust to the particle backscattering coefficient of the remaining aerosol (without the coarse dust backscatter contribution).

In Fig. 9, the dust and non-dust profiles obtained with the one-step method (already discussed in Fig. 8) and the twostep method are compared. As mentioned, in the first round 


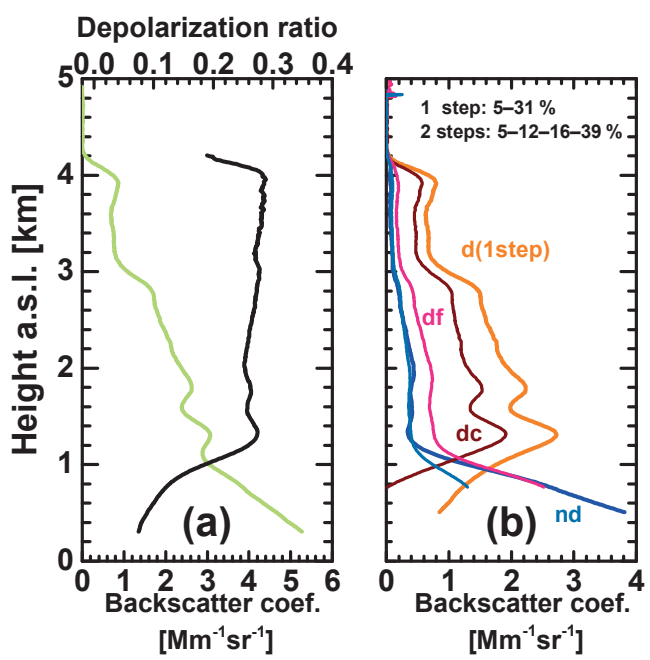

Figure 9. Dust backscatter profiles (in b) obtained by means of the one-step (d(1-step), total dust, orange) and the two-step POLIPHON method (df, fine dust, pink; dc, coarse dust, dark red) applied to the $532 \mathrm{~nm}$ polarization lidar observation of the particle backscatter coefficient (green in panel a) and particle linear depolarization ratio (black in panel a) as already shown in Fig. 7. The non-dust backscatter coefficient profiles (nd in panel $\mathbf{b}$; thick blue is the one-step method; blue is the two-step method) are shown in addition. The one-step method makes use of the characteristic depolarization ratios of 5 (non-dust) and $31 \%$ (dust), whereas the twostep method assumes a height-independent non-dust plus fine-dust depolarization ratio $\left(\delta_{\mathrm{dn}+\mathrm{df}}\right)$ of $12 \%$ and coarse dust depolarization ratio $\left(\delta_{\mathrm{dc}}\right)$ of $39 \%$ in the first round of the retrieval. In the second round, the non-dust depolarization ratio $\left(\delta_{\text {nd }}\right)$ of $5 \%$ and the fine dust depolarization ratio $\left(\delta_{\mathrm{df}}\right)$ of $16 \%$ are used to separate nondust and fine dust backscatter fractions. Solutions of the two-step method are shown for heights $>750 \mathrm{~m}$ (i.e., only for heights with coarse dust (dc) backscatter coefficients $>0 \mathrm{Mm}^{-1} \mathrm{sr}^{-1}$ ).

of the two-step method (Eqs. 5-8), the coarse dust backscatter coefficient $\beta_{\mathrm{dc}}$ is separated from the residual aerosol and in the second round (Eqs. 11-13), we separate the backscatter contributions of non-dust and fine dust. The results of the one-step and the two-step data analysis match well for the total dust backscatter coefficients in the SAL (for heights $>1.2 \mathrm{~km}$ ), indicated in Fig. 9 by the good agreement of the two non-dust backscatter profiles (blue profiles in Fig. 9b). However, within the MAL $(<1.2 \mathrm{~km}$ height $)$ with a changing mixing ratio of marine and dust particles, the solutions of the one-step and the two-step method are no longer in agreement. The profiles for fine and coarse dust become unrealistic and the profile values partly negative (coarse dust values $<0$ at heights $<800 \mathrm{~m}$; not shown in Fig. 9). A fixed $\delta_{\text {nd }+\mathrm{df}, \mathrm{e}}=0.12$ is no longer appropriate at low heights. $\delta_{\mathrm{nd}+\mathrm{df}}$ decreased from 0.12 at $1.4 \mathrm{~km}$ height to 0.06 at $600 \mathrm{~m}$ height, where marine particle backscattering dominates as will be shown below.

In cases with changing mixtures of non-dust and dust aerosol particles, we need an alternative concept. This ap- proach was described in Sect. 4.6 and is illustrated in Fig. 10. It makes use of the solutions of both the one-step and the twostep methods and searches for the most appropriate $\delta_{\text {nd }+ \text { df }}$ in the two-step data analysis (Fig. 10b).

As indicated in Fig. 10b, we use the non-dust depolarization ratio of 0.05 and the dust depolarization ratio of 0.31 in the one-step data analysis and $0.05,0.16$, and 0.39 for the non-dust, fine dust, and coarse dust depolarization ratio, respectively, in the two-step method. The line segments in Fig. 10d, e, and f show the optimum set of fine and coarse dust backscatter profiles (two-step method) and of the total dust backscatter coefficient (one-step solution). The optimum set of fine dust and coarse dust backscatter coefficients for a given height level is found when the total (fine + coarse) dust backscatter coefficient (derived with the two-step method) is equal to the respective dust backscatter coefficient determined with the one-step method (within a tolerable deviation range of up to $\pm 0.05 \mathrm{Mm}^{-1} \mathrm{sr}^{-1}$ ). The optimum solution is determined by varying $\delta_{\text {nd }+ \text { df }}$ between 0.06 and 0.15 (in 0.01 steps) and searching for the $\delta_{\text {nd }+ \text { df }}$ for which the one-step and two-step solutions for the total dust backscatter coefficient match within $\pm 0.05 \mathrm{Mm}^{-1} \mathrm{sr}^{-1}$. As can be seen in Fig. 10b, the orange and the black curve for $\delta_{\text {nd }+ \text { df }}=0.06$ match in the height range from 600 to $650 \mathrm{~m}$. For $\delta_{\text {nd }+\mathrm{df}}=0.08$ and 0.11 , the solutions of the one-step and the two-step methods are equal at around 1000 and $1200 \mathrm{~m}$ height, respectively. The optimum $\delta_{\mathrm{nd}+\mathrm{df}}$ is again 0.11 in the height range from 1900 to $2300 \mathrm{~m}$. The best agreement between the two solutions (orange, black) for heights above $2900 \mathrm{~m}$ is given for $\delta_{\mathrm{nd}+\mathrm{df}}=0.13$. At the end, after analyzing all derived fine, coarse, and total dust backscatter coefficients, height level by height level, we obtain the height profile of $\delta_{\text {nd+df }}$ as shown in Fig. 10c together with the profiles for non-dust, fine dust, and coarse dust backscattering in Fig. 10d. The non-dust backscatter fraction in Fig. 10c shows that non-dust backscattering contributed to about 10-20\% to total particle backscattering in the SAL (1300-2900 m height range). Below the SAL, the non-dust (marine) backscatter contribution rapidly increases towards $80 \%$ in the center of the MBL at $600 \mathrm{~m}$ height.

The mass concentration profiles in Fig. 10f show that coarse dust mostly contributes to particle mass in the SAL and that the non-dust mass concentration is negligibly small here. For simplicity, we assume that marine aerosol are responsibly for the non-dust backscattering. In terms of the climate-relevant particle extinction coefficient, the impact of fine dust is not negligible in the SAL, as shown in Fig. 10e.

Next, we checked the impact of a potential decrease of the coarse dust depolarization ratio from 0.39 to 0.35 as a result of gravitational settling of the larger coarse-mode dust particles during the long-range transport over more than $5000 \mathrm{~km}$. The results are presented in Fig. 11. Here, we assume that the total dust depolarization ratio remains almost unchanged after the long-distance travel and thus is still close to 0.3, as corroborated by the study of Haarig et al. (2017a). It can be 

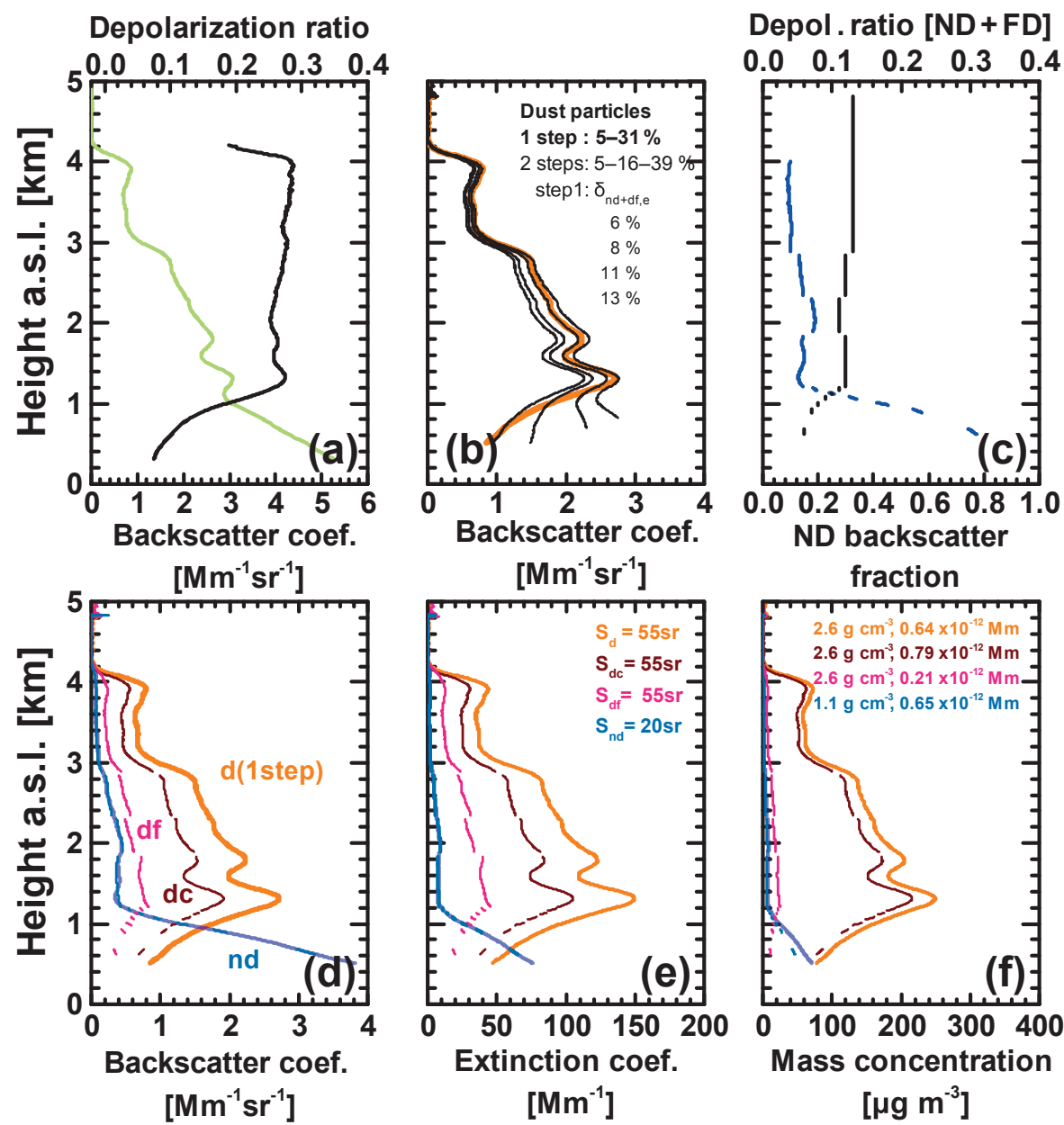

\section{fraction}

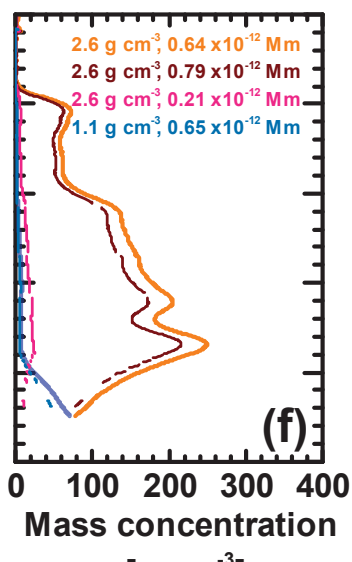

Figure 10. Lidar products (dust and non-dust backscatter, extinction and mass concentrations in panels d, e, and f) obtained from the combined use of the one-step and the two-step POLIPHON method. In (a), the measured $532 \mathrm{~nm}$ particle backscatter coefficient (green) and particle linear depolarization ratio (black, as in Figs. 7 and 9) are shown. In (b), the dust backscatter profile obtained with the one-step method (thick orange) is compared with four profiles of the total (fine + coarse) dust backscatter coefficients derived with the two-step method (thin black lines) by assuming height-independent depolarization ratios, $\delta_{\mathrm{dn}+\mathrm{df}}$ (for non-dust + fine dust aerosol), of $6,8,11$, and $13 \%$ and a value for $\delta_{\mathrm{dc}}$ of $39 \%$ for coarse dust in the first round and depolarization ratios of $\delta_{\text {nd }}$ of $5 \%$ (non-dust) and $\delta_{\mathrm{df}}$ of $16 \%$ (fine dust) in the second round of the two-step retrieval. In (c), the vertical distribution of the optimum $\delta_{\mathrm{dn}+\mathrm{df}}$ (black profile segments), for which the profiles of the dust backscatter coefficients obtained with one-step and two-step methods match within $\pm 0.05 \mathrm{Mm}^{-1} \mathrm{sr}^{-1}$, is shown. In addition, the corresponding profile of the non-dust-to-total particle backscatter ratio (ND backscatter fraction, blue profile segments) is presented. In (d), the retrieved backscatter coefficients are shown, separately for fine dust (df, pink), coarse dust (dc, dark red), total dust (d(1-step), orange, one-step method), and the non-dust aerosol (nd, blue, two profiles, one-step and two-step approaches). In (e), the respective dust and non-dust extinction coefficients are shown. They are obtained by multiplying the backscatter coefficients (in d) with the lidar ratio of $55 \mathrm{sr}$ (dust) and $20 \mathrm{sr}$ (marine). In (f), the total, fine, and coarse dust and marine particle mass concentrations are given, derived from the extinction profiles (in e) by using the conversion factors in Tables 2 and 3. The conversion factors are listed as numbers together with the assumed particle densities in panel (f).

shown by using Eq. (2) in Mamouri and Ansmann (2014) that the combination of a fine dust depolarization ratio of 0.16 and coarse dust depolarization ratio of 0.35 leads to a total dust depolarization ratio around 0.3 only for BFMF of about 0.2 . For the dust-dominating SALTRACE case discussed here, the AERONET FMF values were indeed close to 0.2 so that the coarse-mode depolarization ratio was obviously close to 0.35 and not 0.39 .
Figure 11 now compares the results for both scenarios with $\mathrm{BFMF}=0.2\left(\delta_{\mathrm{dc}}=0.35\right)$ and $0.33\left(\delta_{\mathrm{dc}}=0.39\right)$. As can be seen, a bias of 30-50 and around $20 \%$ must be taken into account in the profiles of the retrieved fine and coarse dust profiles when using a coarse depolarization ratio of 0.35 and the true one is 0.39 or vice versa. These uncertainties are considered in Table 4. Note that in Fig. 11b the one-step solution for the total dust mass concentration coincides (accidentally) 


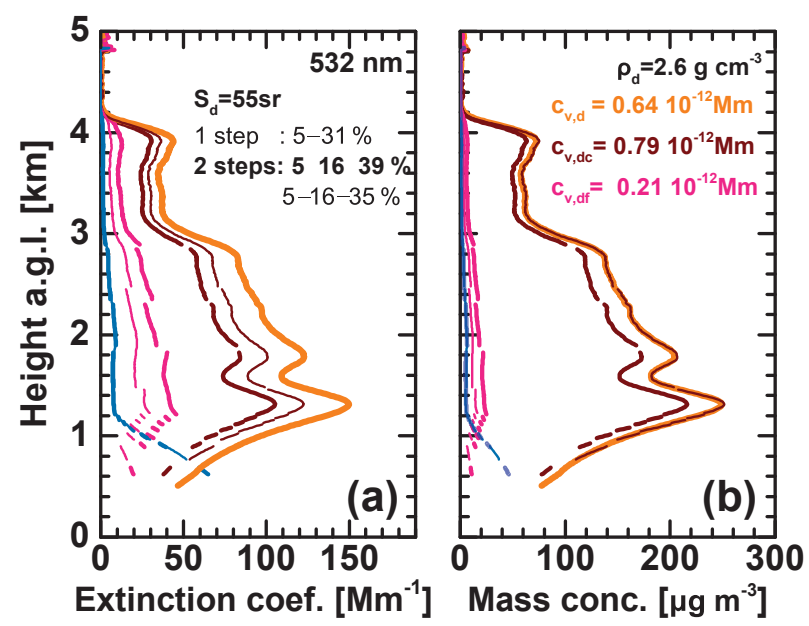

Figure 11. (a) Comparison of fine (pink) and coarse (dark red) dust extinction profiles $(532 \mathrm{~nm})$ obtained with the two-step method for two dust scenarios (scenario 1: thick lines, $\mathrm{BFMF}=0.33$, depolarization ratio combination 5-16-39\%; scenario 2: thin lines, $\mathrm{BFMF}=0.2$, depolarization ratio combination 5-16-35\%). (b) Respective mass concentrations, calculated from the extinction coefficients in (a). The same data analysis (combined use of the one-step and two-step method) as illustrated in Fig. 10 is applied here. The lidar ratio of $55 \mathrm{sr}$ is applied to all (total, fine, coarse) backscatter coefficients to obtain the shown extinction profiles. The blue lines indicate the marine (non-dust) extinction and mass concentration profiles.

with the coarse dust mass concentration profile obtained with the two-step POLIPHON method so that only one profile is clearly visible.

Finally, Fig. 12 shows the attempt to identify the aerosol type causing the non-dust backscatter component (as explained in Sect. 4.4). As can be seen, the profile of the total particle extinction coefficient obtained with the Raman lidar technique is in better agreement with the POLIPHON solution for the mixture of dust and marine particles than for the mixture of dust and anthropogenic particles (with a lidar ratio of $50 \mathrm{sr}$ ).

\subsection{Combined one-step-two-step POLIPHON method at triple wavelengths}

In Fig. 13, the POLIPHON method is now applied to all three lidar wavelengths. The goal is to check whether the full POLIPHON concept, tested in detail for $532 \mathrm{~nm}$ in Figs. 10 and 11, is applicable to 355 and $1064 \mathrm{~nm}$ as well and to evaluate the overall consistency of the entire set of solutions. The second question is, what is the best wavelength for the application of the POLIPHON method?

The results for $532 \mathrm{~nm}$ in Fig. 13 differ from the ones in Fig. 10 because now a coarse dust depolarization ratio of 0.35 instead of 0.39 is assumed. In this way the solutions for the optical properties are in agreement with the AERONET

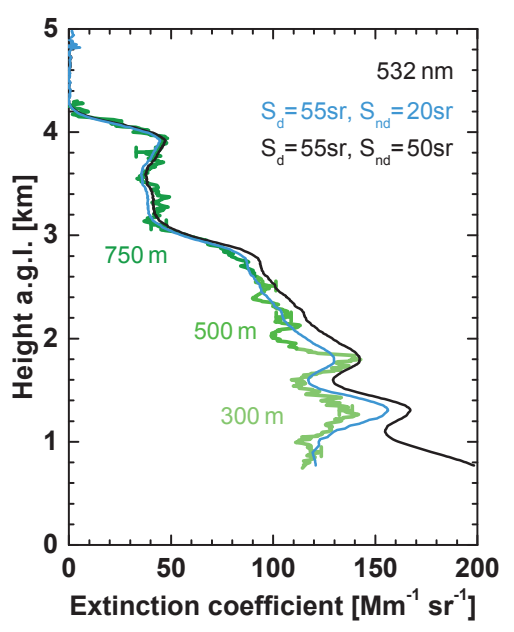

Figure 12. Comparison of the Raman-lidar-derived particle extinction coefficient at $532 \mathrm{~nm}$ (in green) and the POLIPHON extinction coefficient (in blue and black). In the case of the blue POLIPHON profile (for the mixture of dust and marine aerosol) the non-dust backscatter coefficient (in Fig. 10d) is multiplied with a marine lidar ratio of $20 \mathrm{sr}$ and added to the dust backscatter contributions multiplied by a lidar ratio of $55 \mathrm{sr}$. The black curve (for the mixture of dust and anthropogenic aerosol) is obtained when the nondust backscatter component is multiplied with a typical haze and smoke lidar ratio of $50 \mathrm{sr}$ at $532 \mathrm{~nm}$. To reduce the uncertainty by signal noise, signal smoothing with window lengths of $300 \mathrm{~m}$ (up to $2.4 \mathrm{~km}$ height), $500 \mathrm{~m}$ (up to $3 \mathrm{~km}$ ), and $750 \mathrm{~m}$ (above $3 \mathrm{~km}$ ) was applied in the Raman lidar data analysis. Uncertainties are on the order of $10 \%$ (Raman lidar profile, green error bars) and $20 \%$ in the case of the POLIPHON solution.

sun photometer observations, which indicated a FMF (and BFMF) close to 0.2 (see discussion above). It should be mentioned again that a match of the solutions obtained with the one-step and two-step methods is only given for the backscatter coefficients so that the extinction and mass concentration profiles can differ significantly because of the used lidar ratios and extinction-to-volume conversion factors.

The results can be summarized as follows. The overall agreement in Fig. 13 is good, especially for the main dust layer at heights above $2 \mathrm{~km}$. Regarding the dust extinction coefficients, we obtained a strong wavelength dependence for fine dust and a higher coarse dust extinction coefficient at $1064 \mathrm{~nm}$ than at 355 and $532 \mathrm{~nm}$. Note again that the $355 \mathrm{~nm}$ particle depolarization ratios were rather uncertain so that the $355 \mathrm{~nm}$ extinction coefficients and mass concentrations have much larger error bars than the ones shown for $532 \mathrm{~nm}$.

A very good agreement was found in the case of the mass concentrations for coarse and total dust, especially above $2 \mathrm{~km}$ height. Even in the case of fine dust (about an order of magnitude lower mass concentration compared to the coarse dust mass concentration), a very good agreement is obtained for 532 and $1064 \mathrm{~nm}$. Again, the high uncertainty in the $355 \mathrm{~nm}$ particle depolarization ratio may have prohib- 

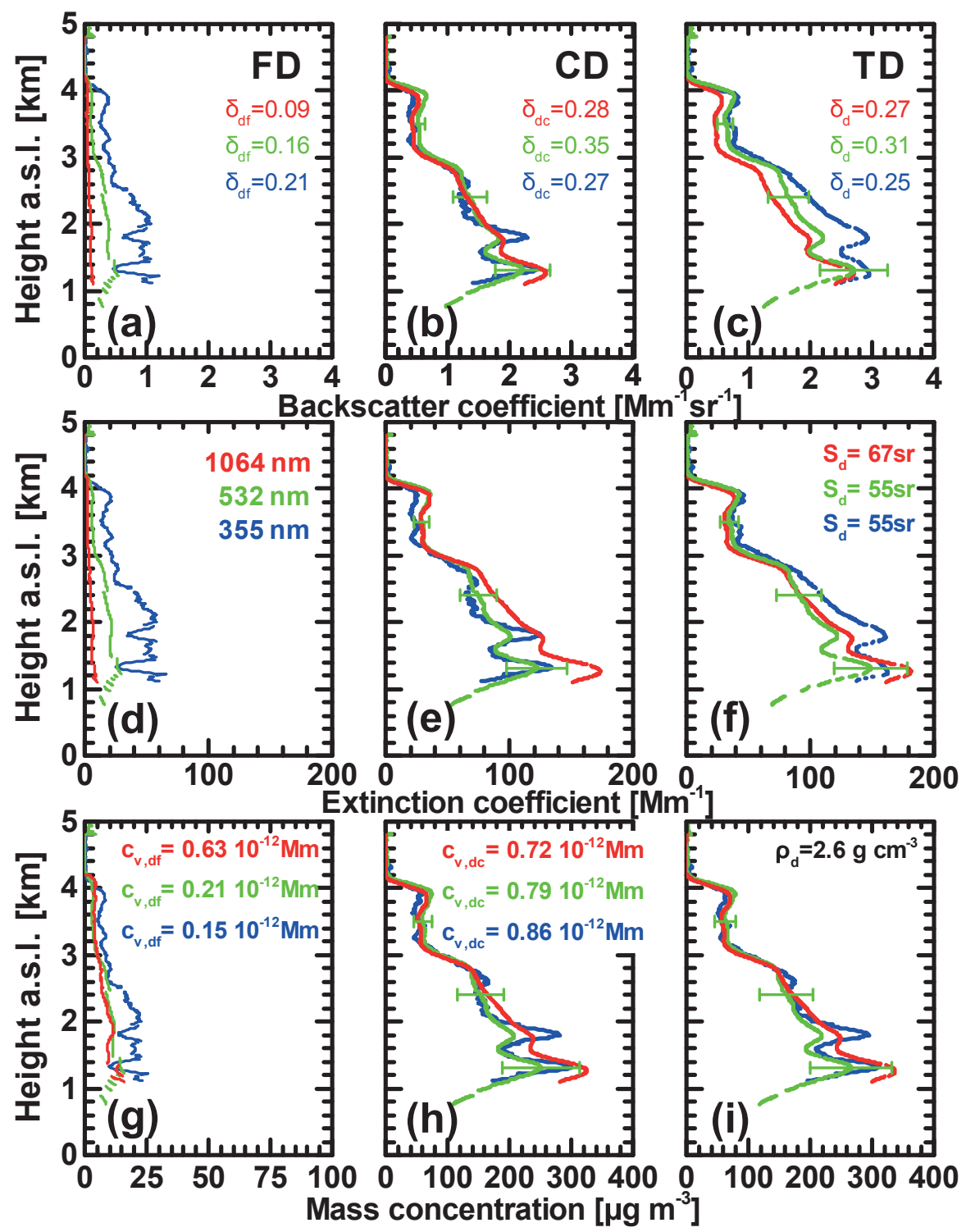

Figure 13. Dust backscatter and extinction coefficients and mass concentrations for fine dust (FD), coarse dust (CD), and total dust (TD) obtained by means of the combined use of the one-step and two-step POLIPHON method, applied to all available polarization lidar data sets $(355 \mathrm{~nm}$ blue, $532 \mathrm{~nm}$, green, $1064 \mathrm{~nm}$, red). For $532 \mathrm{~nm}$ the same solutions as in Fig. 11 (scenario 2) are shown. The dust extinction profiles are computed by multiplying the fine, coarse, and total dust backscatter coefficients with the lidar ratio of $55 \mathrm{sr}(355,532 \mathrm{~nm})$ and $67 \mathrm{sr}(1064 \mathrm{~nm})$. The dust mass concentrations are computed from the extinction coefficients by using the conversion factors in Tables 2 and 3 (given in panels $\mathbf{g}$ and $\mathbf{h}$ ) and the dust particle density (given in panel $\mathbf{i}$ ). Error bars show the overall uncertainty in the case of the coarse and total dust profiles for the $532 \mathrm{~nm}$ solutions.

ited a good match for all three wavelengths. In summary, Fig. 13 demonstrates that the POLIPHON retrieval scheme could successfully be applied to all three lidar wavelengths.

The wavelength of $532 \mathrm{~nm}$ is probably the optimum POLIPHON retrieval wavelength because (a) the contrast between the fine and coarse dust depolarization ratio is highest (much higher than at $355 \mathrm{~nm}$ ), which facilitates the separation of fine dust from coarse dust. When comparing the remaining 532 and $1064 \mathrm{~nm}$ applications we can further state that, (b) in contrast to $1064 \mathrm{~nm}, \mathrm{BFMF}$ at $532 \mathrm{~nm}$ is high enough (usually between 0.15 and 0.35 ) so that fine dust backscattering has a significant impact on the measured lidar signals and can thus be separated with good accuracy. At $1064 \mathrm{~nm}$, BFMF is about $0.05-0.08$ so that an accurate retrieval of fine dust products is generally crucial. (c) The required profile of the $532 \mathrm{~nm}$ particle backscatter coefficient can be obtained with good accuracy, which is a problem at $1064 \mathrm{~nm}$ because of the weak Rayleigh backscattering in the 
backscatter calibration height region. Finally, (d) at $532 \mathrm{~nm}$, typically nitrogen Raman signals are measured in addition (as at $355 \mathrm{~nm}$ ) so that aerosol typing of the non-dust component is possible. This option is not given at $1064 \mathrm{~nm}$. For $532 \mathrm{~nm}$, numerous lidar observations of the lidar ratio for all relevant aerosol types are available for the conversion of the dust and non-dust backscatter into the extinction coefficients. For $1064 \mathrm{~nm}$, such observations are completely absent.

\subsection{Discussion and summary}

We demonstrated that the traditional, well-established onestep and the advanced two-step POLIPHON data analysis techniques are compatible and lead, in principle, to the same results in terms of mass concentrations, disregarding the used lidar wavelength $(355,532$ or $1064 \mathrm{~nm})$. However, the use of $532 \mathrm{~nm}$ signals has many advantages and leads to robust and trustworthy products.

It is recommended to always use both (one-step and twostep) methods in the way shown above, although this approach may not be always fully applicable. It is restricted to conditions with height-independent dust size distribution characteristics (i.e., height-independent fine and coarse dust fractions in the analyzed dust layer). These conditions may be best given in aged dust layers originating from desert dust outbreaks. At simplified, vertically homogeneous, dustdominating conditions we may even omit the use of the twostep method and estimate fine and coarse dust fractions from the total dust extinction coefficient obtained with the simpler one-step approach. The optimum set of fine and coarse dust extinction profiles should then be in agreement with the AERONET observation of the fine-mode AOT fraction.

However, at complex aerosol conditions as described by Mamouri and Ansmann (2014) and Nisantzi et al. (2014) with lofted plumes of biomass-burning smoke and injected soil dust over the local boundary layer with a mixture of urban haze, dust, and marine particles, the two-step method is requested to estimate the fine and coarse dust contributions to the particle extinction coefficient and mass concentration and to obtain an overall consistency in the lidar-photometer observations. Examples of a combined use of the two-step POLIPHON method together with sun photometer observations of AE and FMF during complex aerosol situations were presented in Mamouri and Ansmann (2014). However, even in these complicated cases, comparisons of the results obtained with the one-step and two-step method are recommended to check the overall reliability of the found dust profiles.

One effect needs to be discussed, which can affect our dust separation approach in marine and coastal environments. As shown by Haarig et al. (2017b), marine particles get dry and become cubic in shape when the relative humidity changes from values of $\mathrm{RH}>80 \%$ to values $<50 \%$. At $40-50 \%$, as in our case study at heights from 1.2 to $2.5 \mathrm{~km}$, the depolarization may increases from $2-3 \%$ in the humid MAL to $7-10 \%$ above the MAL. This particle depolarization increase will be misinterpreted as a contribution by dust, when assuming a non-dust depolarization ratio of 0.05 , and thus will lead to an overestimation of dust extinction coefficient and mass concentration profiles. Our analysis showed that this dried marine depolarization effect is not very large in the case we discussed above but must be kept in mind and further explored in future studies.

\section{Conclusions}

We used the unique opportunity of triple-wavelength polarization lidar observations during the SALTRACE field campaigns to test the recently introduced POLIPHON method in detail and extended the application to the three aerosol lidar wavelengths of 355,532 , and $1064 \mathrm{~nm}$. The comparison of the products obtained with the traditional one-step method and the more advanced two-step technique showed the consistency of the overall POLIPHON concept. The extended POLIPHON technique is an important new approach to provide fine $\left(\mathrm{PM}_{1.0}\right)$ and coarse dust profiles $\left(\mathrm{PM}_{10}\right)$ and non-dust aerosol identification (marine or aerosol pollution). Such detailed aerosol profiles are required to better estimate the impact of dust on climate and environmental conditions and to support respective atmospheric modeling and dust forecasting efforts. The technique is simple and robust and can be easily used in ground-based aerosol lidar networks and applied to the spaceborne CALIOP lidar $(532 \mathrm{~nm}$ wavelength) observations as well as to future measurements with the high-spectral-resolution lidar operated at $355 \mathrm{~nm}$ of the EarthCARE mission (Illingworth et al., 2015).

As an open point, it remains to conduct comparisons of the lidar retrievals with respective in situ observations which provide size distributions in the observed dust layers and thus fine and coarse-mode-resolved volume and mass concentrations. More than 10 SALTRACE overflights with a research aircraft (Weinzierl et al., 2017) are available for this task. In April 2017, a dust- and aerosol-pollution-related field campaign with lidar and aircraft was conducted in the highly polluted eastern Mediterranean (Cyprus region), which offers another opportunity for intensive intercomparisons.

The new retrieval technique requires a considerable number of assumptions. The POLIPHON method critically relies on a good knowledge of depolarization ratios and lidar ratios for fine and coarse dust at 355, 532, and $1064 \mathrm{~nm}$. Fortunately, several laboratory and field studies exist that are helping to reduce the number of assumptions on the input parameters. Nevertheless, more laboratory studies including even studies on fine- and coarse-mode dust lidar ratios at the three main lidar wavelengths are required to increase the overall accuracy of the POLIPHON products.

In addition, we need further simulation studies for the mentioned laser wavelengths and for realistic particle shape models. These efforts should focus on particle depolarization 
ratio and lidar ratios for fine dust and coarse dust, separately. Presently, we assumed that the lidar ratio for fine dust and for coarse dust is the same (so that BFMF $=F M F$ ). However, models suggest that the lidar ratio for fine dust is approximately a factor of 2 higher than the coarse dust lidar ratio (Gasteiger et al., 2011; Kemppinen et al., 2015a, b). At these conditions, BFMF would be about a factor of 2 lower and thus roughly 0.5 FMF. Furthermore, the modeling activities have to be extended to characterize the light-depolarizing features of coarse dust particles with diameters from 5 to $20 \mu \mathrm{m}$ and related size parameters of 20 and higher.

Data availability. HYSPLIT backward trajectories are calculated via the available simulation tools (HYSPLIT, 2016). AERONET sun photometer AOT data are downloaded from the AERONET web page (AERONET, 2016). SALTRACE BERTHA lidar data are available at TROPOS (e-mail: albert@ tropos.de).

Competing interests. The authors declare that they have no conflict of interest.

Special issue statement. This article is part of the special issue "The Saharan Aerosol Long-range Transport and Aerosol-CloudInteraction Experiment (SALTRACE) (ACP/AMT inter-journal SI)". It is not associated with a conference.

Acknowledgements. The perfect logistic support of CIMH during the SALTRACE preparation phase and intensive field phases in 2013 and 2014 is gratefully acknowledged. We are grateful to the SALTRACE lidar team of TROPOS at Barbados for providing us with unique polarization lidar observations. We thank the HYSPLIT team for the possibility to compute backward trajectories. We would like to express our special gratitude to the AERONET team for high-quality sun/sky photometer measurements in Cyprus, Germany, Morocco, Cabo Verde, and Barbados and for the high quality data analysis. The authors acknowledge AERONET-Europe for providing calibration service and are grateful to Laurentiu Baschir and the Lidar Calibration Center (Lical), Bucharest, Romania, for excellent service regarding the characterization of lidar optical elements. Both calibration centers are part of the ACTRIS-2 project that received funding from the European Union (H2020-INFRAIA-2014-2015) under grant agreement no. 654109. The authors acknowledge funding from ACTRIS-2 as well as from the EU FP7-ENV-2013 programme "Impact of Biogenic vs. Anthropogenic emissions on Clouds and Climate: towards a Holistic UnderStanding" (BACCHUS), project number 603445.

Edited by: Claire Ryder

Reviewed by: two anonymous referees

\section{References}

Achtert, P. and Tesche, M.: Assessing lidar-based classification schemes for polar stratospheric clouds based on 16 years of measurements at Esrange, Sweden, J. Geophys. Res.-Atmos., 119, 1386-1405, https://doi.org/10.1002/2013JD020355, 2014.

AERONET: AERONET aerosol data base, available at: http:// aeronet.gsfc.nasa.gov/, last access: 20 October 2016.

Althausen, D., Müller, D., Ansmann, A., Wandinger, U., Hube, H., Clauder, E., and Zörner, S.: Scanning sixwavelength eleven channel aerosol lidar, J. Atmos. Ocean. Tech., 17, 1469-1482, https://doi.org/10.1175/15200426(2000)017<1469:SWCAL>2.0.CO;2, 2000.

Amiridis, V., Wandinger, U., Marinou, E., Giannakaki, E., Tsekeri, A., Basart, S., Kazadzis, S., Gkikas, A., Taylor, M., Baldasano, J., and Ansmann, A.: Optimizing CALIPSO Saharan dust retrievals, Atmos. Chem. Phys., 13, 12089-12106, https://doi.org/10.5194/acp-13-12089-2013, 2013.

Ångström, A.: The parameter of atmospheric turbidity, Tellus, 16, 64-75, 1964.

Ansmann, A., Wagner, F., Müller, D., Althausen, D., Herber, A., von Hoyningen-Huene, W., and Wandinger, U.: European pollution outbreaks during ACE 2: Optical particle properties inferred from multiwavelength lidar and star-Sun photometry, J. Geophys. Res., 107, 4259, https://doi.org/10.1029/2001JD001109, 2002.

Ansmann, A., Mattis, I., Müller, D., Wandinger, U., Radlach, M., Althausen, D., and Damoah, R: Ice formation in Saharan dust over central Europe observed with temperature/humidity/aerosol Raman lidar, J. Geophys. Res., 110, D18S12, https://doi.org/10.1029/2004JD005000, 2005.

Ansmann, A., Tesche, M., Althausen, D., Müller, D., Freudenthaler, V., Heese, B., Wiegner, M., Pisani, G., Knippertz, P., and Dubovik, O.: Influence of Saharan dust on cloud glaciation in southern Morocco during SAMUM, J. Geophys. Res., 113, D04210, https://doi.org/10.1029/2007JD008785, 2008.

Ansmann, A., Tesche, M., Knippertz, P., Bierwirth, E., Althausen, D., Müller, D., and Schulz, O.: Vertical profiling of convective dust plumes in southern Morocco during SAMUM, Tellus, 61B, 340-353, 2009a

Ansmann, A., Tesche, M., Seifert, P., Althausen, D., Engelmann, R., Fruntke, J., Wandinger, U., Mattis, I., and Müller, D.: Evolution of the ice phase in tropical altocumulus: SAMUM lidar observations over Cape Verde, J. Geophys. Res., 114, D17208, https://doi.org/10.1029/2008JD011659, 2009b.

Ansmann, A., Tesche, M., Groß, S., Freudenthaler, V., Seifert, P., Hiebsch, A., Schmidt, J., Wandinger, U., Mattis, I., Müller, D., and Wiegner, M.: The 16 April 2010 major volcanic ash plume over central Europe: EARLINET lidar and AERONET photometer observations at Leipzig and Munich, Germany, Geophys. Res. Lett., 37, L13810, https://doi.org/10.1029/2010GL043809, 2010.

Ansmann, A., Tesche, M., Seifert P, Groß, S., Freudenthaler, V., Apituley, A., Wilson, K. M., Serikov, I., Linné, H., Heinold, B., Hiebsch, A., Schnell, F., Schmidt, J., Mattis, I., Wandinger, U., and Wiegner, M.: Ash and fine-mode particle mass profiles from EARLINET-AERONET observations over central Europe after the eruptions of the Eyjafjallajökull volcano in 2010, J. Geophys. Res., 116, D00U02, https://doi.org/10.1029/2010JD015567, 2011 a. 
Ansmann, A., Petzold, A., Kandler, K., Tegen, I., Wendisch, M., Müller, D., Weinzierl, B., Müller, T., and Heintzenberg, J.: Saharan mineral dust experiments SAMUM-1 and SAMUM-2: What have we learned?, Tellus B, 63, 403-429, https://doi.org/10.1111/j.1600-0889.2011.00555.x, 2011b.

Ansmann, A., Seifert, P., Tesche, M., and Wandinger, U.: Profiling of fine and coarse particle mass: case studies of Saharan dust and Eyjafjallajökull/Grimsvötn volcanic plumes, Atmos. Chem. Phys., 12, 9399-9415, https://doi.org/10.5194/acp12-9399-2012, 2012.

Ansmann, A., Rittmeister, F., Engelmann, R., Basart, S., Benedetti, A., Spyrou, C., Skupin, A., Baars, H., Seifert, P., Senf, F., and Kanitz, T.: Profiling of Saharan dust from the Caribbean to West Africa, Part 2: Shipborne lidar measurements versus forecasts, Atmos. Chem. Phys. Discuss., https://doi.org/10.5194/acp-2017502, in review, 2017.

Bravo-Aranda, J. A., Belegante, L., Freudenthaler, V., AladosArboledas, L., Nicolae, D., Granados-Muñoz, M. J., GuerreroRascado, J. L., Amodeo, A., D’Amico, G., Engelmann, R., Pappalardo, G., Kokkalis, P., Mamouri, R., Papayannis, A., N avasGuzmán, F., Olmo, F. J., Wandinger, U., Amato, F., and Haeffelin, M.: Assessment of lidar depolarization uncertainty by means of a polarimetric lidar simulator, Atmos. Meas. Tech., 9, 49354953, https://doi.org/10.5194/amt-9-4935-2016, 2016.

Bissonnette, L. R.: Lidar and multiple scattering, in: LIDAR Range-resolved optical remote sensing of the atmosphere, edited by: Weitkamp, C., Springer, New York, 43-103, 2005.

Browell, E., Butler, C., Ismail, S., Robinette, P., Carter, A., Higdon, N., Toon, O., Schoeberl, M., and Tuck, A.: Airborne lidar observations in the wintertime Arctic stratosphere: Polar stratospheric clouds, Geophys. Res. Lett., 17, 385-388, https://doi.org/10.1029/GL017i004p00385, 1990.

Burton, S. P., Ferrare, R. A., Hostetler, C. A., Hair, J. W., Rogers, R. R., Obland, M. D., Butler, C. F., Cook, A. L., Harper, D. B., and Froyd, K. D.: Aerosol classification using airborne High Spectral Resolution Lidar measurements - methodology and examples, Atmos. Meas. Tech., 5, 73-98, https://doi.org/10.5194/amt-5-732012, 2012.

Burton, S. P., Ferrare, R. A., Vaughan, M. A., Omar, A. H., Rogers, R. R., Hostetler, C. A., and Hair, J. W.: Aerosol classification from airborne HSRL and comparisons with the CALIPSO vertical feature mask, Atmos. Meas. Tech., 6, 13971412, https://doi.org/10.5194/amt-6-1397-2013, 2013.

Burton, S. P., Hair, J. W., Kahnert, M., Ferrare, R. A., Hostetler, C. A., Cook, A. L., Harper, D. B., Berkoff, T. A., Seaman, S. T., Collins, J. E., Fenn, M. A., and Rogers, R. R.: Observations of the spectral dependence of linear particle depolarization ratio of aerosols using NASA Langley airborne High Spectral R esolution Lidar, Atmos. Chem. Phys., 15, 13453-13473, https://doi.org/10.5194/acp-15-13453-2015, 2015.

Cairo, F., Di Donfrancesco, G., Adriani, A., Lucio, P., and Federico, F.: Comparison of various linear depolarization parameters measured by lidar, Appl. Opt. 38, 4425-4432, 1999.

Chaikovsky, A., Dubovik, O., Holben, B., Bril, A., Goloub, P., Tanré, D., Pappalardo, G., Wandinger, U., Chaikovskaya, L., Denisov, S., Grudo, J., Lopatin, A., Karol, Y., Lapyonok, T., Amiridis, V., Ansmann, A., Apituley, A., Allados-Arboledas, L., Binietoglou, I., Boselli, A., D’Amico, G., Freudenthaler, V., Giles, D., Granados-Muñoz, M. J., Kokkalis, P., Nicolae, D., Os- hchepkov, S., Papayannis, A., Perrone, M. R., Pietruczuk, A., Rocadenbosch, F., Sicard, M., Slutsker, I., Talianu, C., De Tomasi, F., Tsekeri, A., Wagner, J., and Wang, X.: Lidar-Radiometer Inversion Code (LIRIC) for the retrieval of vertical aerosol properties from combined lidar/radiometer data: development and distribution in EARLINET, Atmos. Meas. Tech., 9, 1181-1205, https://doi.org/10.5194/amt-9-1181-2016, 2016.

Chouza, F., Reitebuch, O., Jähn, M., Rahm, S., and Weinzierl, B.: Vertical wind retrieved by airborne lidar and analysis of island induced gravity waves in combination with numerical models and in situ particle measurements, Atmos. Chem. Phys., 16, 46754692, https://doi.org/10.5194/acp-16-4675-2016, 2016.

Donovan, D. P., Klein Baltink, H., Henzing, J. S., de Roode, S. R., and Siebesma, A. P.: A depolarisation lidar-based method for the determination of liquid-cloud microphysical properties, Atmos. Meas. Tech., 8, 237-266, https://doi.org/10.5194/amt-8237-2015, 2015.

Dubovik, O., Smirnov, A., Holben, B. N., King, M. D., Kaufman, Y. J., Eck, T. F., and Slutsker, I.: Accuracy assessments of aerosol optical properties retrieved from Aerosol Robotic Network (AERONET) Sun and sky radiance measurements, J. Geophys. Res., 105, 9791-9806, https://doi.org/10.1029/2000JD900040, 2000.

Franke, K., Ansmann, A., Müller, D., Althausen, D., Venkataraman, C., Reddy, M. S., Wagner, F., and Scheele, R.: Optical properties of the Indo-Asian haze layer over the tropical Indian Ocean, J. Geophys. Res., 108, 4059, https://doi.org/10.1029/2002JD002473, 2003.

Freudenthaler, V., Esselborn, M., Wiegner, M., Heese, B., Tesche, M., Ansmann, A., Müller, D., Althausen, D., Wirth, M., Fix, A., Ehret, G., Knippertz, P., Toledano, C., Gasteiger, J., Garhammer, M., and Seefeldner, M.: Depolarization ratio profiling at several wavelengths in pure Saharan dust during SAMUM 2006, Tellus B, 61, 165-179, https://doi.org/10.1111/j.16000889.2008.00396.x, 2009.

Freudenthaler, V.: About the effects of polarising optics on lidar signals and the $\Delta 90$ calibration, Atmos. Meas. Tech., 9, 41814255, https://doi.org/10.5194/amt-9-4181-2016, 2016.

Gasteiger, J., Wiegner, M., Groß, S., Freudenthaler, V., Toledano, C., Tesche, M., and Kandler, K.: Modelling lidar-relevant optical properties of complex mineral dust aerosols, Tellus B, 63, 725-741, https://doi.org/10.1111/j.16000889.2011.00559.x, 2011.

Gasteiger, J., Groß, S., Sauer, D., Haarig, M., Ansmann, A., and Weinzierl, B.: Particle settling and vertical mixing in the Saharan Air Layer as seen from an integrated model, lidar, and in situ perspective, Atmos. Chem. Phys., 17, 297-311, https://doi.org/10.5194/acp-17-297-2017, 2017.

Gobbi, G. P.: Polarization lidar returns from aerosols and thin clouds: a framework for the analysis, Appl. Opt. 37, 5505-5508, 1998.

Gobbi, G. P., Barnaba, F., Giorgo, R., and Santacasa, A.: Altituderesolved properties of a Saharan dust event over the Mediterranean, Atmos. Environ., 34, 5119-5127, 2000.

Groß, S., Tesche, M., Freudenthaler, V., Toledano, C., Wiegner, M., Ansmann, A., Althausen, D., and Seefeldner, M.: Characterization of Saharan dust, marine aerosols and mixtures of biomassburning aerosols and dust by means of multi-wavelength depolarization and Raman lidar measurements during SA- 
MUM 2, Tellus B, 63, 706-724, https://doi.org/10.1111/j.16000889.2011.00556.x, 2011.

Groß, S., Freudenthaler, V., Wiegner, M., Gasteiger, J., Geiß, and Schnell F.: Dual-wavelength linear depolarization ratio of volcanic aerosols: Lidar measurements of the Eyjafjallajökull plume over Maisach, Germany, Atmos. Environ., 48, 85-96, 2012.

Groß, S., Esselborn, M., Weinzierl, B., Wirth, M., Fix, A., and Petzold, A.: Aerosol classification by airborne high spectral resolution lidar observations, Atmos. Chem. Phys., 13, 2487-2505, https://doi.org/10.5194/acp-13-2487-2013, 2013.

Groß, S., Freudenthaler, V., Schepanski, K., Toledano, C., Schäfler, A., Ansmann, A., and Weinzierl, B.: Optical properties of long-range transported Saharan dust over Barbados as measured by dual-wavelength depolarization Raman lidar measurements, Atmos. Chem. Phys., 15, 11067-11080, https://doi.org/10.5194/acp-15-11067-2015, 2015.

Haarig, M., Althausen, D., Ansmann, A., Klepel, A., Baars, H., Engelmann, R., Groß, S., and Freudenthaler, V.: Measurement of the linear depolarization ratio of aged dust at three wavelengths $(355,532$ and $1064 \mathrm{~nm})$ simultaneously over Barbados, EPJ Web of Conferences, 119, 18009, ILRC 27, https://doi.org/10.1051/epjconf/201611918009, 2016a.

Haarig, M., Engelmann, R., Ansmann, A., Veselovskii, I., Whiteman, D. N., and Althausen, D.: $1064 \mathrm{~nm}$ rotational Raman lidar for particle extinction and lidar-ratio profiling: cirrus case study, Atmos. Meas. Tech., 9, 4269-4278, https://doi.org/10.5194/amt9-4269-2016, 2016b.

Haarig, M., Ansmann, A., Althausen, D., Klepel, A., Groß, S., Freudenthaler, V., Toledano, C., Mamouri, R.-E., Farrell, D. A., Prescod, D. A., Marinou, E., Burton, S. P., Gasteiger, J., Engelmann, R., and Baars, H.: Triple-wavelength depolarizationratio profiling of Saharan dust over Barbados during SALTRACE in 2013 and 2014, Atmos. Chem. Phys., 17, 10767-10794, https://doi.org/10.5194/acp-17-10767-2017, 2017a.

Haarig, M., Ansmann, A., Gasteiger, J., Kandler, K., Althausen, D., Baars, H., and , Farrell, D.: Dry versus wet marine particle optical properties: $\mathrm{RH}$ dependence of depolarization ratio, backscatter and extinction from multiwavelength lidar measurements during SALTRACE, Atmos. Chem. Phys. Discuss., https://doi.org/10.5194/acp-2017-545, in review, 2017b.

Hande, L. B., Engler, C., Hoose, C., and Tegen, I.: Parameterizing cloud condensation nuclei concentrations during HOPE, Atmos. Chem. Phys., 16, 12059-12079, https://doi.org/10.5194/acp-1612059-2016, 2016.

Heintzenberg, J.: The SAMUM-1 experiment over Southern Morocco: overview and introduction, Tellus B, 61, 2-11, 2009.

Hofer, J., Althausen, D., Abdullaev, S. F., Makhmudov, A. N., Nazarov, B. I., Schettler, G., Engelmann, R., Baars, H., Fomba, K. W., Müller, K., Heinold, B., Kandler, K., and Ansmann, A.: Long-term profiling of mineral dust and pollution aerosol with multiwavelength polarization/Raman lidar at the Central Asian site of Dushanbe, Tajikistan: Case studies, Atmos. Chem. Phys. Discuss., https://doi.org/10.5194/acp-2017-559, in review, 2017.

Holben, B. N., Eck, T. F., Slutsker, I., Tanré, D., Buis, J. P., Setzer, A., Vermote, E., Reagan, J. A., Kaufman, Y. J., Nakajima, T., Lavenu, F., Jankowiak, I., and Smirnov, A.: AERONET - a federated instrument network and data archive for aerosol characterization, Remote Sens. Environ., 66, 1-16, 1998.
Huneeus, N., Schulz, M., Balkanski, Y., Griesfeller, J., Prospero, J., Kinne, S., Bauer, S., Boucher, O., Chin, M., Dentener, F., Diehl, T., Easter, R., Fillmore, D., Ghan, S., Ginoux, P., Grini, A., Horowitz, L., Koch, D., Krol, M. C., Landing, W., Liu, X., Mahowald, N., Miller, R., Morcrette, J.-J., Myhre, G., Penner, J., Perlwitz, J., Stier, P., Takemura, T., and Zender, C. S.: Global dust model intercomparison in AeroCom phase I, Atmos. Chem. Phys., 11, 7781-7816, https://doi.org/10.5194/acp11-7781-2011, 2011.

HYSPLIT: HYbrid Single-Particle Lagrangian Integrated Trajectory model, backward trajectory calculation tool, available at: http://ready.arl.noaa.gov/HYSPLIT_traj.php, last access: 20 October 2016.

Iwasaka, Y., and Hayashida, S.: The effects of the volcanic eruption of St. Helens on the polarization properties of stratospheric aerosols: Lidar measurement at Nagoya, J. Meteorol. Soc. Jpn., 59, 611-614, 1981

Illingworth, A. J., Barker, H. W., Beljaars, A., Ceccaldi, M., Chepfer, H., Clerbaux, N., Cole, J., Delanoe, J., Domenech, C., Donovan, D. P., Fukuda, S., Hirakata, M., Hogan, R. J., Huenerbein, H., Kollias, P., Kubota, T., Nakajima, T., Nakajima, T. Y., Nishizawa, T., Ohno, Y., Okamoto, H., Oki, R., Sato, K., Satoh, M., Shephard, M., Velázquez-Blázquez, A., Wandinger, U., Wehr, T., and Zadelhoff, G.-J.: The EarthCARE satellite: the next step forward in global measurements of clouds, aerosols, precipitation and radiation, B. Am. Meteorol. Soc., 96, 1311-1332, https://doi.org/10.1175/BAMS-D-12$00227.1,2015$.

Järvinen, E., Kemppinen, O., Nousiainen, Kociok, T., Möhler, O., Leisner, T., and Schnaiter, M.: Laboratory investigations of mineral dust near-backscattering depolarization ratios, J. Quant. Spectrosc. Ra., 178, 192-208, https://doi.org/10.1016/j.jqsrt.2016.02.003.

Kanitz, T., Seifert, P., Ansmann, A., Engelmann, R., Althausen, D., Casiccia, C., and Rohwer, E. G.: Contrasting the impact of aerosols at northern and southern midlatitudes on heterogeneous ice formation, Geophys. Res. Lett., 38, L17802, https://doi.org/10.1029/2011GL048532, 2011.

Kanitz, T., Engelmann, R., Heinold, B., Baars, H., Skupin, A., and Ansmann, A.: Tracking the Saharan air layer with shipborne lidar across the tropical Atlantic, Geophys. Res. Lett., 41, 4762-4766, https://doi.org/10.1002/2013GL058780, 2014.

Kemppinen, O., Nousiainen, T., and Jeong, G. Y.: Effects of dust particle internal structure on light scattering, Atmos. Chem. Phys., 15, 12011-12027, https://doi.org/10.5194/acp-15-120112015, 2015a.

Kemppinen, O., Nousiainen, T., and Lindqvist, H.: The impact of surface roughness on scattering by realistically shaped wavelength-scale dust particles, J. Quant. Spectrosc. Ra., 150, 55-67, https://doi.org/10.1016/j.jqsrt.2014.05.024, 2015 b.

Kim, D., Chin, M., Yu, H., Diehl, T., Tan, Q., Kahn, R. A., Tsigaridis, K., Bauer, S. E., Takemura, T., Pozzoli, L., Bellouin, N., Schulz, M., Peyridieu, S., Chédin, A., and Koffi, B.: Sources, sinks, and transatlantic transport of North African dust aerosol: A multimodel analysis and comparison with remote sensing data, J. Geophys. Res.-Atmos., 119, 6259-6277, https://doi.org/10.1002/2013JD021099, 2014.

Koffi, B., Schulz, M., Bréon, F.-M., Griesfeller, J., Winker, D. M., Balkanski, Y., Bauer, S., Berntsen, T., Chin, M., Collins, W. 
D., Dentener, F., Diehl, T., Easter, R. C., Ghan, S. J., Ginoux, P. A., Gong, S., Horowitz, L. W., Iversen, T., Kirkevag, A., Koch, D. M., Krol, M., Myhre, G., Stier, P., and Takemura, T.: Application of the CALIOP layer product to evaluate the vertical distribution of aerosols estimated by global models: Part 1. AeroCom phase I results, J. Geophys. Res., 117, D10201, https://doi.org/10.1029/2011JD016858, 2012.

Koffi, B., Schulz, M., Bréon, F.-M., Dentener, F., Steensen, B. M., Griesfeller, J., Winker, D., Balkanski, Y., Bauer, S. E., Bellouin, N., Berntsen, T., Bian, H., Chin, M., Diehl, T., Easter, R., Ghan, S., Hauglustaine, D. A., Iversen, T., Kirkevag, A., Liu, X., Lohmann, U., Myhre, G., Rasch, P., Seland, O., Skeie, R. B., Steenrod, S. D., Stier, P., Tackett, J., Takemura, T., Tsigaridis, K., Vuolo, M. R., Yoon, J., and Zhang, K.: Evaluation of the aerosol vertical distribution in global aerosol models through comparison against CALIOP measurements: AeroCom phase II results, J. Geophys. Res.-Atmos., 121, 7254-7283, https://doi.org/10.1002/2015JD024639, 2016.

Kok, J. F.: A scaling theory for the size distribution of emitted dust aerosols suggests climate models underestimate the size of the global dust cycle, P. Natl. Acad. Sci. USA, 108, 1016-1021, https://doi.org/10.1073/pnas.1014798108, 2011.

Kok, J. F., Ridley, D. A., Zhou, Q., Miller, R. L., Zhao, C., Heald, C. L., Ward, D. S., Albani, S., and Haustein, K.: Smaller desert dust cooling effect estimated from analysis of dust size and abundance, Nat. Geosci., 10, 274-278, https://doi.org/10.1038/ngeo2912, 2017

Kristensen, T. B., Müller, T., Kandler, K., Benker, N., Hartmann, M., Prospero, J. M., Wiedensohler, A., and Stratmann, F.: Properties of cloud condensation nuclei $(\mathrm{CCN})$ in the trade wind marine boundary layer of the western North Atlantic, Atmos. Chem. Phys., 16, 2675-2688, https://doi.org/10.5194/acp-162675-2016, 2016.

Lindqvist, H., Jokinen, O., Kandler, K., Scheuvens, D., and Nousiainen, T.: Single scattering by realistic, inhomogeneous mineral dust particles with stereogrammetric shapes, Atmos. Chem. Phys., 14, 143-157, https://doi.org/10.5194/acp-14-143-2014, 2014.

Lopatin, A., Dubovik, O., Chaikovsky, A., Goloub, P., Lapyonok, T., Tanré, D., and Litvinov, P.: Enhancement of aerosol characterization using synergy of lidar and sun-photometer coincident observations: the GARRLiC algorithm, Atmos. Meas. Tech., 6, 2065-2088, https://doi.org/10.5194/amt-6-2065-2013, 2013.

Mahowald, N., Albani, S., Kok, J. F., Engelstaeder, S., Scanza, R., Ward, D. S., and Flanner, M. G.: The size distribution of desert dust aerosols and its impact on the Earth system, Aeolin Res., 15, 53-71, https://doi.org/10.1016/j.aeolia.2013.09.002, 2014.

Mamouri, R. E., Ansmann, A., Nasantzi, A., Kokkalis, P., Schwarz, A., and Hadjimitsis, D.: Low Arabian extinctionto-backscatter ratio, Geophys. Res. Lett., 40, 4762-4766, https://doi.org/10.1002/grl.50898, 2013.

Mamouri, R. E. and Ansmann, A.: Fine and coarse dust separation with polarization lidar, Atmos. Meas. Tech., 7, 3717-3735, https://doi.org/10.5194/amt-7-3717-2014, 2014.

Mamouri, R. E. and Ansmann, A.: Estimated desert-dust ice nuclei profiles from polarization lidar: methodology and case studies, Atmos. Chem. Phys., 15, 3463-3477, https://doi.org/10.5194/acp-15-3463-2015, 2015.
Mamouri, R.-E. and Ansmann, A.: Potential of polarization lidar to provide profiles of $\mathrm{CCN}$ - and INP-relevant aerosol parameters, Atmos. Chem. Phys., 16, 5905-5931, https://doi.org/10.5194/acp-16-5905-2016, 2016.

Mann, G. W., Carslaw, K. S., Reddington, C. L., Pringle, K. J., Schulz, M., Asmi, A., Spracklen, D. V., Ridley, D. A., Woodhouse, M. T., Lee, L. A., Zhang, K., Ghan, S. J., Easter, R. C., Liu, X., Stier, P., Lee, Y. H., Adams, P. J., Tost, H., Lelieveld, J., Bauer, S. E., Tsigaridis, K., van Noije, T. P. C., Strunk, A., Vignati, E., Bellouin, N., Dalvi, M., Johnson, C. E., Bergman, T., Kokkola, H., von Salzen, K., Yu, F., Luo, G., Petzold, A., Heintzenberg, J., Clarke, A., Ogren, J. A., Gras, J., Baltensperger, U., Kaminski, U., Jennings, S. G., O’Dowd, C. D., Harrison, R. M., Beddows, D. C. S., Kulmala, M., Viisanen, Y., Ulevicius, V., Mihalopoulos, N., Zdimal, V., Fiebig, M., Hansson, H.-C., Swietlicki, E., and Henzing, J. S.: Intercomparison and evaluation of global aerosol microphysical properties among AeroCom models of a range of complexity, Atmos. Chem. Phys., 14, 4679-4713, https://doi.org/10.5194/acp-14-4679-2014, 2014.

McNeil, W. R. and Carswell, A. I.: Lidar polarization studies of the troposphere, Appl. Opt. 14, 2158-2168, 1975.

Miffre, A., David, G., Thomas, B., Rairoux, P., Fjaeraa, A. M., Kristiansen, N. I., and Stohl, A.: Volcanic aerosol optical properties and phase partitioning behavior after long-range advection characterized by UV-Lidar measurements, Atmos. Environ., 48, 7684, 2012.

Müller, D., Mattis, I., Ansmann, A., Wandinger, U., Ritter, C., and Kaiser, D.: Multiwavelength Raman lidar observations of particle growth during long-range transport of forest-fire smoke in the free troposphere, Geophys. Res. Lett., 34, L05803, https://doi.org/10.1029/2006GL027936, 2007.

Murayama, T., Okamoto, H., Kaneyasu, N., Kamataki, H., and Miura, K.: Application of lidar depolarization measurement in the atmospheric boundary layer: Effects of dust and sea-salt particles, J. Geophys. Res., 104, 31781-31792, https://doi.org/10.1029/1999JD900503, 1999.

Murayama, T., Müller, D., Wada, K., Shimizu, A., Sekiguchi, M., and Tsukamoto, T.: Characterization of Asian dust and Siberian smoke with multiwavelength Raman lidar over Tokyo, Japan in spring 2003, Geophys. Res. Lett., 31, L23103, https://doi.org/10.1029/2004GL021105, 2004.

Nabat, P., Solmon, F., Mallet, M., Kok, J. F., and Somot, S.: Dust emission size distribution impact on aerosol budget and radiative forcing over the Mediterranean region: a regional climate model approach, Atmos. Chem. Phys., 12, 10545-10567, https://doi.org/10.5194/acp-12-10545-2012, 2012.

Nickovic, S., Cvetkovic, B., Madonna, F., Rosoldi, M., Pejanovic, G., Petkovic, S., and Nikolic, J.: Cloud ice caused by atmospheric mineral dust - Part 1: Parameterization of ice nuclei concentration in the NMME-DREAM model, Atmos. Chem. Phys., 16, 11367-11378, https://doi.org/10.5194/acp-16-113672016, 2016.

Nishizawa, T., Okamoto, H., Sugimoto, N., Matsui, I., Shimizu, A., and Aoki, K.: An algorithm that retrieves aerosol properties from dual-wavelength polarized lidar measurements, J. Geophys. Res., 112, D06212, https://doi.org/10.1029/2006JD007435, 2007.

Nisantzi, A., Mamouri, R. E., Ansmann, A., and Hadjimitsis, D.: Injection of mineral dust into the free troposphere during fire events observed with polarization lidar at Limassol, Cyprus, Atmos. 
Chem. Phys., 14, 12155-12165, https://doi.org/10.5194/acp-1412155-2014, 2014.

Nisantzi, A., Mamouri, R. E., Ansmann, A., Schuster, G. L., and Hadjimitsis, D. G.: Middle East versus Saharan dust extinctionto-backscatter ratios, Atmos. Chem. Phys., 15, 7071-7084, https://doi.org/10.5194/acp-15-7071-2015, 2015.

Omar, A. H., Winker, D. M., Vaughan, M. A., Hu, Y., Trepte, C. R., Ferrare, R. A., Lee, K., Hostetler, C. A., Kittaka, C., Rogers, R. R., Kuehn, R. E., and Liu, Z.: The CALIPSO Automated Aerosol Classification and Lidar Ratio Selection Algorithm. J. Atmos. Ocean. Technol., 26, 1994-2014, https://doi.org/10.1175/2009JTECHA1231.1, 2009.

Prospero, J. M. and Mayol-Bracero, O. L.: Understanding the transport and impact of African dust on the Caribbean Basin, B. Am. Meteorol. Soc., 94, 1329-1337, https://doi.org/10.1175/BAMSD-12-00142.1, 2013.

Reichardt, J., Reichardt, S., Hess, M., and McGee, T. J.: Correlations among the optical properties of cirrus-cloud particles: Microphysical interpretation, J. Geophys. Res., 107, 4562, https://doi.org/10.1029/2002JD002589, 2002.

Reichardt, J., Reichardt, S., Lin, R.-F., Hess,M., McGee, T. J., and Starr, D. O.: Optical-microphysical cirrus model, J. Geophys. Res., 113, D22201, https://doi.org/10.1029/2008JD010071, 2008.

Ridley, D. A., Heald, C. L., Kok, J. F., and Zhao, C.: An observationally constrained estimate of global dust aerosol optical depth, Atmos. Chem. Phys., 16, 15097-15117, https://doi.org/10.5194/acp-16-15097-2016, 2016.

Rittmeister, F., Ansmann, A., Engelmann, R., Skupin, A., Baars, H., Kanitz, T., and Kinne, S.: From the Caribbean to West Africa: Four weeks of continuous dust and marine aerosol profiling with shipborne polarization/Raman lidar - a contribution to SALTRACE, Atmos. Chem. Phys. Discuss., https://doi.org/10.5194/acp-2017-130, in review, 2017.

Sakai, T., Shibata, T., Hara, K., Kido, M., Osada, K., Hayashi, M., Matsunaga, K., and Iwasaka, Y.: Raman lidar and aircraft measurements of tropospheric aerosol particles during the Asian dust event over central Japan: Case study on 23 April 1996, J. Geophys. Res., 108, 4349, https://doi.org/10.1029/2002JD003150, 2003.

Sakai, T., Nagai, T., Zaizen, Y, and Mano, Y.: Backscattering linear depolarization ratio measurements of mineral, sea-salt, and ammonium sulfate particles simulated in a laboratory chamber, Appl. Opt., 49, 4441-4449, 2010.

Sassen, K.: The polarization lidar technique for cloud research: A review and current assessment, B. Am. Meteorol. Soc., 72, 18481866, 1991.

Sassen, K., DeMott, P. J., Prospero, J. M., and Poellot, M. R.: Saharan dust storms and indirect aerosol effects on clouds: CRYSTAL-FACE results, Geophys. Res. Lett., 30, 1633, https://doi.org/10.1029/2003GL017371, 2003.

Sassen, K., Polarization in lidar, in: LIDAR - Range-resolved optical remote sensing of the atmosphere, edited by: Weitkamp, C., Springer, New York, 19-42, 2005.

Sassen, K., Zhu, J., Webley, P., Dean, K., and Cobb, P.: Volcanic ash plume identification using polarization lidar: Augustine eruption, Alaska, Geophys. Res. Lett., 34, L08803, https://doi.org/10.1029/2006GL027237, 2007.
Seifert, P., Ansmann, A., Mattis, I., Wandinger, U., Tesche, M., Engelmann, R., Müller, D., Pérez, C., and Haustein, K.: Saharan dust and heterogeneous ice formation: eleven years of cloud observations at a central European EARLINET site, J. Geophys. Res., 115, D20201, https://doi.org/10.1029/2009JD013222, 2010.

Seifert, P., Ansmann, A., Groß, S., Freudenthaler, V., Heinold, B., Hiebsch, A., Mattis, I., Schmidt, J., Schnell, F., Tesche, M., Wandinger, U., and Wiegner, M.: Ice formation in ashinfluenced clouds after the eruption of the Eyjafjallajökull volcano in April 2010, J. Geophys. Res., 116, D00U04, https://doi.org/10.1029/2011JD015702, 2011.

Shimizu, A., Sugimoto, N., Matsui, I., Arao, K., Uno, I., Murayama, T., Kagawa, N., Aoki, K., Uchiyama, A., and Yamazaki, A.: Continuous observations of Asian dust and other aerosols by polarization lidars in China and Japan during ACE-Asia, J. Geophys. Res., 109, D19S17, https://doi.org/10.1029/2002JD003253, 2004.

Sugimoto, N., Uno, I., Nishikawa, M., Shimizu, A., Matsui, I., Dong, X., Chen, Y., and Quan, H.: Record heavy Asian dust in Beijing in 2002: Observations and model analysis of recent events, Geophys. Res. Lett., 30, 1640, https://doi.org/10.1029/2002GL016349, 2003.

Tesche, M., Ansmann, A., Müller, D., Althausen, D., Engelmann, R., Freudenthaler, V., and Groß, S.: Vertically resolved separation of dust and smoke over Cape Verde using multiwavelength Raman and polarization lidars during Saharan Mineral Dust Experiment 2008, J. Geophys. Res., 114, D13202, https://doi.org/10.1029/2009JD011862, 2009a.

Tesche, M., Ansmann, A., Müller, D., Althausen, D., Mattis, I., Heese, B., Freudenthaler, V., Wiegner, M., Esselborn, M., Pisani, G., and Knippertz, P.: Vertical profiling of Saharan dust with Raman lidars and airborne HSRL in southern Morocco during SAMUM, Tellus B, 61, 144-164, https://doi.org/10.1111/j.16000889.2008.00390.x, 2009b.

Tesche, M., Groß, S., Ansmann, A., Müller, D., Althausen, D., Freudenthaler, V., and Esselborn, M.: Profiling of Saharan dust and biomass-burning smoke with multiwavelength polarization Raman lidar at Cape Verde, Tellus B, 63, 649-676, https://doi.org/10.1111/j.1600-0889.2011.00548.x, 2011a.

Tesche, M., Müller, D., Groß, S., Ansmann, A., Althausen, D., Freudenthaler, V., Weinzierl, B., Veira, A., and Petzold, A.: Optical and microphysical properties of smoke over Cape Verde inferred from multiwavelength lidar measurements, Tellus B, 63, 677-694, https://doi.org/10.1111/j.1600-0889.2011.00549.x, $2011 b$.

Toledano, C., Wiegner, M., Garhammer, M., Seefeldner, M., Gasteiger, J., Müller, D., and Koepke, P.: Spectral aerosol optical depth characterization of desert dust during SAMUM 2006, Tellus B, 61, 216-228, https://doi.org/10.1111/j.16000889.2008.00382.x, 2009.

Toledano, C., Wiegner, M., Groß, S., Freudenthaler, V., Gasteiger, J., Müller, D., Müller, T., Schladitz, A., Weinzierl, B., Torres, B., and O'Neill, N. T.: Optical properties of aerosol mixtures derived from sun-sky radiometry during SAMUM-2, Tellus B, 63, 635648, https://doi.org/10.1111/j.1600-0889.2011.00573.x, 2011.

Toledano, C., Bennouna, Y., Cachorro, V., Ortiz de Galisteo, J. P., Stohl, A., Stebel, K., Kristiansen, N. I., Olmo, F. J., Lyamani, H., Obregón, M. A., Estellés, V., Wagner, F., Baldasano, J. 
M., González-Castanedo, Y., Clarisse, L., and de Frutos, A. M.: Aerosol properties of the Eyjafjallajökull ash derived from sun photometer and satellite observations over the Iberian Peninsula, Atmos. Environ., 48, 22-32, 2012.

Toledano, C., Torres, B., Althausen, D., Groß, S., Freudenthaler, V., Weinzierl, B., Gasteiger, J., Ansmann, A., Wiegner, M., González, R., Fuertes, D., Velasco, C., Mateos, D., Burgos, M. A., and Cachorro, V. E.: Sun photometer retrievals of Saharan dust properties over Barbados during SALTRACE, Atmos. Chem. Phys. Discuss., in preparation, 2017.

Torres, B., Dubovik, O., Fuertes, D., Schuster, G., Cachorro, V. E., Lapionak, T., Goloub, P., Blarel, L., Barreto, A., Mallet, M., Toledano, C., and Tanré, D.: Advanced characterization of aerosol properties from measurements of spectral optical depth using the GRASP algorithm, Atmos. Meas. Tech. Discuss., https://doi.org/10.5194/amt-2016-334, in review, 2016.

Veselovskii, I., Goloub, P., Podvin, T., Bovchaliuk, V., Derimian, Y., Augustin, P., Fourmentin, M., Tanré, D., Korenskiy, M., Whiteman, D. N., Diallo, A., Ndiaye, T., Kolgotin, A., and Dubovik, O.: Retrieval of optical and physical properties of African dust from multiwavelength Raman lidar measurements during the SHADOW campaign in Senegal, Atmos. Chem. Phys., 16, 70137028, https://doi.org/10.5194/acp-16-7013-2016, 2016.

Wandinger, U., Müller, D., Böckmann, C., Althausen, D., Matthias, V., Bösenberg, J, Weiß, V., Fiebig, M., Wendisch, M., Stohl, A., and Ansmann. A.: Optical and microphysical characterization of biomass-burning and industrial-pollution aerosols from multiwavelength lidar and aircraft measurements, J. Geophys. Res., 107, LAC7-1-LAC7-20, https://doi.org/10.1029/2000JD000202, 2002.
Weinzierl, B., Ansmann, A, Prospero, J. M., Althausen, D., Benker, N., Chouza, F., Dollner, M., Farrell, D., Fomba, W. K., Freudenthaler, V., Gasteiger, J., Groß, S., Haarig, M., Heinold, B., Kandler, K., Kristensen, T. B., Mayol-Bracero, O.-L., Müller, T., Reitebuch, O., Sauer, D., Schäfler, A., Schepanski, K., Tegen, I., Toledano, C., and Walser, A.: The Saharan Aerosol Longrange TRansport and Aerosol Cloud Interaction Experiment (SALTRACE): overview and selected highlights, B. Am. Meteorol. Soc., 98, 1427-1451, https://doi.org/10.1175/BAMS-D-1500142.1, 2017.

Winker, D. M. and Osborn, M. T.: Preliminary analysis of observations of the Pinatubo volcanic plume with a polarization-sensitive lidar, Geophys. Res. Lett., 19, 171-174, https://doi.org/10.1029/91GL02866, 1992

Winker, D. M., Vaughan, M. A., Omar, A., Hu, Y., Powell, K. A., Liu, Z., Hunt, W. H., and Young, S. A.: Overview of the CALIPSO mission and CALIOP data processing algorithms, J. Atmos. Ocean. Tech., 26, 2310-2323, 2009.

Zhang, L., Kok, J. F., Henze, D. K., Li, Q., and Zhao, C.: Improving simulations of fine dust surface concentrations over the western United States by optimizing the particle size distribution, Geophys. Res. Lett., 40, 3270-3275, https://doi.org/10.1002/grl.50591, 2013. 